\title{
La cuestión de la especificidad de la mujer en Edith Stein (1891-1942)
}

\author{
Anneliese Meis \\ PONTIFICIA UNIVERSIDAD CATÓLICA DE CHILE
}

Hay preguntas que siempre se formulan de nuevo a lo largo de todos los tiempos sin que las podamos dejar atrás definitivamente. Una de esas preguntas es el problema de la especificidad de la mujer, planteada desde que existimos en cuanto varón y mujer, pero actualmente replanteada con una virulencia tal, que las respuestas literalmente nos desbordan, como si nunca hubiésemos encarado esta cuestión. Ante este panorama desafiante, Edith Stein, mujer pensadora potente de nuestro tiempo ${ }^{1}$, nos plantea dos preguntas que están en la base de toda cuestión referente a la mujer. En primer lugar: ¿cuál es el método científico que aportará resultados certeros a esta cuestión? En segundo lugar: ¿se puede definir científicamente la especificidad de la mujer, es decir, abordar una figura concreta siendo siempre lo abstracto el campo propio de la ciencia?

Las respuestas de Edith Stein son múltiples y multifacéticas y cobran una singular actualidad in crescendum a través de las alusiones diseminadas en sus escritos de muy diversa índole y profundidad ${ }^{2}$. Ante la imposibilidad de abordar la totalidad de los enfoques steinianos, optamos por un acercamiento a la especificidad de la mujer desde un eje articulador,

1 Para los datos biográficos Cf. E. Stein, Selbstbildnis I, II, III (ESG, 3) Freiburg, Basel, Wien 2000. En la vida de Edith Stein pueden distinguirse tres períodos: El período fenomenológico (1916-1923): el período pedagógico-neotomista (1922-1938); el período místico (1938-1942).

2 E. Stein Gesamtausgabe, Herausgegeben im Auftrag des Internationalen Edith Stein Instituts Würzburg Freiburg-Basel-Wien 2004-2008; E. STEIN, Obras completas, bajo la dirección de Julen Urkiza y Francisco Javier Sancho, Burgos 2002-2005; v. 1. Escritos autobiográficos y cartas -- v. 2. Escritos filosóficos (Etapa fenomenológica: 1915-1920) -- v. 4. Escritos antropológicos y pedagógicos (Magisterio de vida cristiana, 1926-1933) -- v. 5. Escritos espirituales (En el Carmelo Teresiano: 19331942). 
que consideramos central en las respuestas de Edith Stein, siguiendo las indicaciones metodológicas de la misma autora ${ }^{3}$. Tal eje emerge desde la mención del Espíritu Santo en relación con la mujer y lo femenino hasta llegar a una cierta identificación entre ambos aspectos ${ }^{4}$. En efecto, dicho eje se plasma al interior de la estructura de la persona humana, allí donde el hontanar del espíritu humano borbotea desde "el alma del alma".

En sus obras tempranas Edith Stein designa esta "alma del alma" Gemüt, mientras posteriormente resalta solo el sentir Füblen, sin que el Ge-

3 Las indicaciones más relevantes para nuestra pregunta se encuentran en los siguientes obras, Die Frau Fragestellungen und Reflexionen (=F)(ESG 13/1) FreiburgBasel-Wien 2000,153-166; Einführung in die Philosopohie(=EP)(ESG 8/4) Freiburg-Basel-Wien 200415-22; Der Aufbau der menschlichen Person.Vorlesungen zur philosophischen, Anthropologie(=AP) (ESG 14,2) Freiburg-Basel-Wien 2004, 26-29; Potenz und Akt .Studien zu einer Phlosophie des Seins(=PA)(ESG 10/2) Freiburg-Basel-Wien 2005, 18-20; Endliches und ewiges Sein. Versuch eines Aufstiegs zum Sinn des Seins (=EES) (ESG 11/12) Freiburg-Basel-Wien 2006,9-36. Cf. Introducción a la Filosofía, Obras Completas I, 680-687; La estructura de la persona humana, 46-50.

4 E. Stein, Die Frau.Fragestellungen und Reflexionen (=F) (ESG 13/1), FreiburgBasel-Wien 2000, 105: wenn auf der anderen Seite in der männlichen Natur der Verstand vorherrschend ist, in der Frau das Gemüt, so versteht man es, dass immer wieder der Versuch gemacht wird, die weibliche Natur in eine besondere Verbindung mit dem Hl.Geist zu bringen.Cf. F 178-179, EES 430ss. Para el método Cf. LEMBECK K.H., De la crítica a la mística. Edith Stein y el neokantinismo de Marburgo, Anuario Filosófico 31 ( 1998)689-708; Secreta Philibert, Erkenntnis und Aufstieg. Einführung in die Philosophie von Edith Stein, Innsbruck-Wien- Würzburg, 1992, $147 \mathrm{pp}$.

5 AP 129: Die "Seele der Seele" ist etwas Geistiges; und die Seele als Ganzes ein geistiges Wesen, dessen Eigenümlichkeit es ist, ein Inneres zu haben, im Zentrum, von dem sie ausgehen muss, um Gegenstände zu begegnen, in das sie heimträgt, was sie von ausssen gewinnt, und aus dem sie selbst nach aussen spenden kann. Hier ist das Zentrum des menschlichen Daseins". Se trata de la interioridad del ser humano, designado también ápice, que como tal evoca cierta similitud con la noción de "genio", proveniente de gino, DA 458: -.Geistes-Gemütsart f.Genie (geniale ) Veranlagung 2.Genie gr.geist.3.(innerstes) Wesen,n Geist 4.Rel Genius,geist Schutzgeist.: Gemüt: facultades afectivas; alma; ánimo, corazón, hacer algo sentir vivamente.; Gemütsbeschaffenheit, carácter, genio; temperamento, naturaleza, disposición natural. Juan Pablo II usa la expresión "genio femenino" para ofrecer una intelección adecuada de la cuestión de la mujer y como tal los documentos magisteriales la aplican desde Mulieris Dignitatem hasta el Documento Conclusivo de Aparecida Cf. DC 458a. Se constata al respecto cierta cercanía al planteamiento de Edith Stein, Cf. Allen PRUDENCE, Can Feminism be a Humanism, Ëtudes maritainiennes-Maritain Studies, 14 (1998) 109-140. 
müt, en definitiva, desaparezca ${ }^{6}$, ya que Gemüt involucra una de las ideas más centrales del pensamiento steiniano: la alteridad ${ }^{7}$. Desde esta profundidad y orientada hacia ella abordaremos la cuestión de la especificidad de la mujer en busca de una respuesta aproximativa a la pregunta metodológica: ¿en qué medida la noción de "Gemüt-genio-sentimiento-ánimoemotividad-entrañeza" posibilita una comprensión adecuada de la alteridad y su misterio en el Espíritu Santo, según Edith Stein? Elaboremos los siguientes tres aspectos:

1. Aproximación metodológica a la especificidad de la mujer

2. El origen fundante trinitario de la especificidad femenina

3. La especificidad de la mujer en cuanto "mujer no solo mujer"

6 AP 129: Die deutsche Sprache hat dafür das Wort "Gemüt". Wenn sie dafür auch Seele sagt, so ist es die "Seele der Seele", das, worin sie jeweils bei sich selbst ist, worin sie sich findet und so findet wie sie ist und wie sie jeweils gestimmt ist; worin sie aber auch das, was sie mit den Sinnen und dem Verstand aufasst innerlich aufnimmt, es in seiner Bedeutung erfasst und sich damit auseinandersetzt, es bewahrt und daraus Kraft schöpft oder auch davon angegriffen wird"-El Gemüt tiene sus raíces etimológicas clásicas muy antiguas: "Das seit mhd Zeit bezeugte Wort (mhd gemúte) ist eine Kollektivbildung zu dem unter Mut behandelten Substantiv und bezeignete zunächst die Gesamtheit der seelischen Empfindungen und Gedanken, dann auch den Sitz der inneren Empfindugen und Gedanken (gemütlich typisch deutsch). DuDEN, Etimologie, 210: el término atestiguado desde el tiempo $m b d$ (mhd.gemüete) es una formación colectiva del Mut como sustantivo (Mut: 458: el término germano común mhd,ahdmuot, got mobs, engl.mood, schwed, mod, pertenece junto con palabras parecidas en otros idiomas idg a la raíz verba l-me, mo: apetecer algo, anhelar algo fuertemente, estar excitados cf. p.e.gr.mosthal, "streben" trachten, begehren y lat mos, costumbre, Brauch,Gewohnheit, originariamente voluntad) (s.moral). Probablemente tiene parentesco con el grupo de términos múhen y designó primordialmente la totalidad de los sentimientos anímicos y pensamientos, luego también la sede de los sentimientos internos y de los pensamientos. Se trata de un término difícil de traducir, parecido a genio-sentimiento-ánimo-emotividad o tal vez mejor, “entrañeza”, un neologismo creado por GonzÁlez de Cardenal Olegario, La entraña del Cristianismo, 2.ed. Salamanca 1998, 745, 873-874. Cf. C.M. StubBemann, Edith Stein: lo femenino y su vivencia en la espiritualidad, Revista de Espiritualidad 60 (2001), 259-254.

7 T. van Den Driessche, L'Altérité, Fondement de la personne bumaine dans l'oeuvre d'Edith Stein, (Bibliotheca Ephemeirdum Theologicarum Lovanaienneisum, 212) LeuvenParis-Dudley, MA 2008, 626pp. Para una mejor comprensión del pensamiento de Edith Stein Cf. A. U. Müller, Einführung, E. Stein, Endliches und ewiges Sein, (ESG 11/12, XIII-XLIII). 


\section{Aproximación metodológica a la especificidad de la mujer}

Partimos con el esfuerzo de entender por qué Edith Stein se separa de Husserl. ¿Cuál es la causa? Sin duda está en juego la pregunta fundamental: ¿cómo acceder a la realidad? Y, más precisamente, ¿qué es la realidad? Evocamos un momento significativo del diálogo que se produjo entre Husserl y su acompañante, una religiosa benedictina, durante un momento de lucidez en la grave enfermedad del "Maestro": cuando ella le recordó que "en el principio era el Verbo [...]" y él contestó: "En el principio está el “yo" $[\ldots]^{8}$ Lo que queda claro en este diálogo es la persistencia husserliana en la "mónada", que invalidó su propio descubrimiento de la "vuelta a las cosas", pero que Edith Stein rescató por "el otro" y "el Otro" gracias al nexo metodológico, que ella establece entre Filosofía y Teología. Tal nexo -no su oposición- es indispensable para poder desvelar la especificidad de la mujer, cuestión afectada de modo especial por descuidos metodológicos?. Por cierto, el método de las ciencias empíricas no basta ${ }^{10}$, ya que dicha cuestión, que Edith Stein sitúa ponderadamente

8 E. Stein, Selbstbildnis in Briefen II (ESG, 3) Freiburg, Basel, Wien 2000, 298: Adelgundis Jaegerchmid an Edith Stein. Cf. R. FeIst, W. SweEt, Husserl und Stein (Cultural heritage and Contempory change Series 1, Culture and value, Volumen 31, Washington 2003, 201 pp.; P. VolEK, Erkenntnistheorie bei Edith Stein. Metaphysische Grundlagen der Erkenntnis bei Edith Stein im Vergleich zu Husserl und Thomas von Aquin (Europäische Hochschulschriften, 564) Frankfurt am Main-BerlinBern-New York-Paris-Wien 1998, 245 pp.

9 Cf. F, La Mujer 190: 'Por lo que respecta a la cuestión de la investigación sobre la especificidad femenina, sobre ello se ha producido en los últimos años una extensa literatura. Hasta qué punto, empero, tenemos que vérnoslas con una investigación metodológicamente segura, o hasta qué punto, con intentos diletantes, eso sería demasiado decir todavía. Puesto que este análisis tendremos que acometerlo detalladamente muy pronto, me gustaría decir anticipadamente hoy que hay quizá pocos ámbitos sobre cuyos métodos se haya hablado y escrito con tanta ingenua seguridad y tan descuidadamente. Y por eso me parece que la elaboración seria y científica está todavía en sus primeros comienzos".

10 Cf. Fundamentos teóricos de la formación de la mujer, 44: "La pregunta por la diversidad esencial de género, en principio no se puede solucionar a través de un tratamiento científico-experimental (fisiológica o psicológica). Pertenece al conjunto de una antropología filosófica, que ha puesto de relieve la esencia del hombre con los medios cognoscitivos específicos de la filosofía, y ha alcanzado la posibilidad de delimitar el sentido y el método de las ciencias empíricas que se ocupan del hombre. La radical consideración filosófica se topa con sus propios límites, aquí y en todas partes: nos encontramos con cuestiones que no tienen solución, ni por caminos empíricos ni filosóficos. (Ahí pertenecen las cuestiones sobre el origen, tanto del hombre individual como de la humanidad). 
en el conjunto de las ciencias"11 "supera las posibilidades naturales de la razón humana $[\ldots]$ se necesita la luz sobrenatural de la revelación" para "una elaboración de la imagen del hombre que está contenida en nuestra doctrina de la fe" ${ }^{\text {"12 }}$.

\section{a. El método adecuado para el abordaje de la especificidad de la mujer}

El acercamiento a la cuestión de la especificidad de la mujer requiere de una mirada receptiva activa, a la vez que un "ir a las cosas"-que revela la objetividad de la esencia de todo cuanto existe en la "constitución" subjetiva del yo puro-, una vez puesto entre paréntesis -epoché- lo sabido, hasta los "pensamiento del corazón”. Avanza así más allá de los conceptos claros y distintos por medio de la "intuición husserliana" hasta la "verdad" objetiva, que emerge en las estructuras multidimensionales del sujeto, capaz de abordar la singularidad concreta de lo femenino en la mujer, siendo la conciencia siempre una "conciencia de...".

En efecto, Edith Stein opta por la ontología, que ella considera la “disciplina fundamental, es decir, una teoría de las formas fundamentales del ser y del ente" ${ }^{13}$. Pues dicha ontología "puede mostrar que dentro del ser hay un corte radical: el corte entre un ser puro, que no contiene en sí nada del no ser, que no tiene ningún principio y ningún fin, y que incluye en sí todo lo que puede ser, y un ser finito, que comienza y cesa, que está dado a un ente finito. Llamamos al uno ser increado; al otro ser creado,

11 La mujer, 218-233: "Hemos visto ahora una serie de métodos diferentes con los cuales se intenta o podría intentarse seguir la huella de la especificidad de la mujer. Una vez más tenemos que resumir viendo qué pueden aportar cada uno de ellos -conforme a los medios epistemológicos de que hacen uso- para la solución de nuestros problemas." Las aportaciones de los métodos, exactas, humanas, filosóficas, teológicas al conocimiento del sujeto: mujer determinan qué sea la especie correspondiente a la función epistemológica propia de la filosofia, y solo a ella puede corresponderle. Para mostrar mínimamente cómo me planteo la solución de la tarea, debo ordenarla en la totalidad de la problemática filosófica, tal como la veo.

12 Cf. Fundamentos teóricos de la formación de la mujer, 44: "Se lo puede desvelar a la luz sobrenatural de la revelación. Se le ha dado al hombre expresamente con la finalidad de que no esté en la incertidumbre sobre su origen y su meta, así como sobre los caminos que le puede conducir a la meta. Así, la antropología filosófica por sí misma desea un complemento por medio de una antropología teológica, es decir, una elaboración de la imagen del hombre que está contenida en nuestra doctrina de la fe.

13 La mujer, 218ss F 161: F 160: Wie ich bereits an früherer Stelle sagte, sehe ich als Fundamentaldiszipin die Ontologie an, d.h. eine Lehre von den Grundformen des Seins und des Seienden. 
ente; al ser correspondiente al primero, creador, y al ser correspondiente al segundo, criatura" ${ }^{\prime 4}$.

A la luz de este trasfondo que puede sonar teológico, pero que es filosófico ${ }^{15}$, Edith Stein explica: "Las criaturas se inordenan en grados según su mayor o menor cercanía al ser puro. Pues todo ser creador es un análogo del divino. La analogia entis, empero, es distinta para cada grado. A cada grado corresponde un diverso modo de ser y una diversa forma fundamental de los entes: ser material, orgánico, animal, espiritual. En cada escala, el ser humano ocupa una posición particular, en la medida en que en la estructura de su ser están contenidos todos los grados más bajos. Su carne es un cuerpo material, pero no solo eso, sino a la vez un organismo que está formado y es operante desde el interior; y de nuevo el ser humano no es solamente organismo, sino un ser viviente animado, que de un modo particular -perceptivamente- está abierto a sí mismo y al entorno; y finalmente es un ser espiritual, que se encuentra abierto cognoscitivamente a sí mismo y a los otros, y que puede libremente dar forma a sí mismo y a los otros"16.

Resumiendo lo expuesto respecto a la ubicación del ser humano en

${ }^{14}$ F 161 Sie kann zeigen, dass es innerhalb des Seins einen radikalen Schnitt gibt: den Schnitt zwischen einem reinen Sein, das nichts von Nicht-Sein in sich hält, das keinen Anfang und kein Ende hat und alles in sich befasst, was sein kann, und einem endlichen Sein, das anfängt und aufhört, das einem endlichen Seienden zugeteilt ist. Wir nennen das eine das ungeschaffene, das andere das geschaffene Sein, das Seiende, das dem einen und dem andern entspricht, den Schöpfer und die Geschöpfe.

15 F 161 (Diese Ausdrücke sind der Sprache der Theologie entnommen, aber das Sachliche, das damit bezeichnet wird, lässt sich rein philosophische aufzeigen). Explica la autora: "Estas expresiones son tomadas del lenguaje de la teología, pero la realidad que con ellas se expresa puede considerarse puramente filosófica".

16 La mujer 218ss F 161: Die Geschöpfe ordnen sich in Stufen je nach der grösseren oder geringeren Annäherung, die sie zum reinen Sein haben. Denn alles geschöpfliche Sein ist ein Analogon des göttlichen. Die analogia entis (Seinsanalogie) ist aber für jede Stufe eine andere. Jeder Stufe entspricht eine andere Art des Seins und eine andere Grundform des Seienden: materielles, organisches, animalisches, geistiges Sein. In diesem Stufenbau nimmt der Mensch eine eigentümliche Stellung ein, indem in seinem Wesensbau alle niedren Stufen enthalten sind. Sein Leib ist ein materieller Körper, aber nicht nur das, sondern zugleich ein Organismus, der von innen her geformt wird und tätig ist, und wiederum ist der Mensch nicht nur Organismus, sondern ein beseeltes Lebewesen, das in eigentúmlicher Weise- empfindungsmässig-für sich selbst und für anderes erkenntnismässig- für sich selbst und seine Umwelt aufgeschlossen ist, und schliesslich ein geistiges Wesen, das fúr sich selbst und für anderes frei tätig gestalten kann. 
la graduación de los entes y su constitución estructural abierta, la autora insiste: "Todo esto pertenece a la especie ser humano, y aquello que no muestra esta estructura esencial no puede ser llamado ser humano. Sin embargo, esta especie se nos presenta diferenciada en los individuos: cada ser humano, salvada su específica naturaleza humana, tiene una peculiaridad irrepetible. La filosofía puede mostrar que también la individualidad, en el sentido de la irrepetibilidad, le pertenece a la especie humana, aunque analizar cada individualidad no es cosa de la filosofía, sino de una función experiencial específica de la que hacemos uso cotidianamente en el contacto con los seres humanos. Esta diferenciación de la humanidad en una pluralidad ilimitada de individualidades está entrelazada con otra simple: la diferenciación sexual ${ }^{\prime 17}$. Emerge aquí la irrepetibilidad de la individualidad humana como a la vez diferenciada sexualmente.

Frente a esta diferencia sexual, marcada por la irrepetibilidad individual, Edith Stein advierte: “Todavía quisiera resaltar las cuestiones siguientes... ¿hay que entender la distinción entre hombre y mujer de tal manera que toda la estructura del ser humano como tal esté realmente cortada por la diferenciación sexual, o afecta la diferenciación solo a la carne y aquellas funciones anímicas que necesariamente están unidas a órganos carnales, mientras el espíritu debe ser considerado libre de todos eso, una idea que ha sido defendida de muchas maneras no solo en los círculos de mujeres, sino también por muchos teólogos?... Además, si en cada individuo están ambos incluidos, lo masculino y lo femenino, y en todo caso solo lo uno o lo otro predomina, ¿necesitarían entonces los individuos de ambas especies para expresar plenamente la esencia del ser humano?, ¿no podría ella alcanzar su expresión plena en un único individuo?"18.

17 La mujer, 220 nota 26 F 161: All das gehört zur Species des Menschen, und was nicht diesen Wesensaufbau zeigt, kann nicht "Mensch" genannt werden. Diese Species tritt uns aber in den Individuen differenziert entgegen: jeder Mensch hat unbeschadet seiner spezifischen Menschennatur eine unwiederholbare Eigenart. Die Philosophie kann noch die Individualität,im Sinne von Einzigartigkeit, als zur Species des Menschen gehörig aufzeigen; die jeweilige Individualität zu erfassen, ist nicht ihre Sache, sondern die einer spezifischen Erfahrungsfunktion, von der wir im Umgang mit Menschen täglich Gebrauch machen. Diese Differenzierung des Menschentums zu einer unbegrenzten Vielheit von Individualitäten wird durchschnitten von einer anderen, einfachen: der geschlechtlichen Differenzierung.

18 La mujer, 222 F 163: Ich möchte jetzt noch folgende Fragen [...] hervorheben: Ist der Unterschied von Mann und Frau so zu fassen, dass wirklich die gesamte Struktur des Menschen als solchen durch die geschlechtliche Differenzierung geschnitten wird oder betrifft die Differenzierung nur den Leib und diejenige seelische 
La autora responde enfáticamente sus preguntas cuando declara: "Soy de la convicción de que la especie ser humano se desarrolla como especie doble $^{19}$, hombre y mujer, de que la esencia del ser humano, a la cual no puede faltar ningún rasgo ni aquí ni allí, alcanza a expresarse de dos mo-

Funktionen, die notwendig an leibliche Organe gebunden sind, und kann der Geist als davon frei angesehen werden (eine Auffassung, die nicht nur vielfach in Frauenkreisen, sondern auch von manchen Theologen vertreten wird (Note39)?Wäre die zweite Auffassung haltbar, dann dürfte Geistesbildung weitgehend ohne Rücksicht auf Geschletschunterschiede angestrebt werden; im andern fall müsste die Bildungsarbeit der spezifischen Struktur des geistes Rechnung tragen.Ferner: Wenn in jedem Individuum beides-Männliches und Weibliches-beschlossen ist und nur jeweils eine oder andere überwiegt, bedarf es dann Individuen beider "Species", um die Species des Menschen vollkommen auszuprägen? Könnte sie nicht in einem einzigen Individuum zur vollen Ausprägung der spezifischen Natur einzustellen sein wird.

19 Cf. La mujer 205-206 para la aclaración de conceptos básicos como especie, etc.: Hablé antes de la especie mujer. Bajo especie hay que entender aquí algo fijo, que no cambia. La filosofía tomista emplea también para ello la expresión forma, y con ello menta una forma interior, que determina la estructura de una realidad. El tipo no inalterable en el mismo sentido que la especie [...] En la medida, empero, en que se trata de una forma interior, a tales influencias se le ponen límites. La forma interior o especie circunscribe un arco de juego dentro del cual el tipo puede variar: Está bien claro, pues, que la pregunta por la especie mijer es la pregunta básica de todas las preguntas sobre la mujer. Si existe una especie semejante, entonces no podrá ser cambiada por ninguna alteración de las condiciones de vida, de las relaciones económicas y comerciales, y de la propia actividad, que son por su parte cambiantes. Si no existe ninguna especie semejante, entonces hay que ver a hombre y mujer no como especies, sino solo como tipos en el sentido que nosotros hemos delimitado, y entonces es posible en ciertas condiciones el paso de un tipo al otro. Esto no es tan absurdo como podría parecer a simple vista. Antaño se ha tenido la opinión de que las condiciones físicas debían ser fijas, aunque se veía a las anímicas como variablemente ilimitadas, pero incluso contra la invariabilidad de las diferencias corporales pueden aducirse ciertos datos fácticos, tales como las formas de androginismo y de mutación de sexo". "Esta pregunta básica de todas las preguntas sobre la mujer nos remite, empero, a los principios de la filosofía. Para poderla resolver satisfactoriamente hay que tener claridad sobre la relación de género, especie, tipo e individuo, es decir, sobre los problemas fundamentales de la ontología formal, en la que yo veo aquello que buscaba Aristóteles con su filosofía primera. Lo que de esta disciplina fundamental se obtiene en su generalidad formal tienen que buscarlo las disciplinas naturales en determinados ámbitos especializados. La investigación de la esencia de la mujer tiene su lugar lógico en una antropología filosófica. A la teoría sobre el ser humano le corresponde la clarificación del sentido de la diferenciación sexual, el establecimiento del contenido de la especie, además de la posición de la especie en la construcción del individuo humano, de la relación en la construcción del individuo humano, de la relación de los tipos con la especie e individuos, y de las condiciones de la formación de los tipos. 
dos diversos; y de que solo la totalidad de su constructo esencial evidencia su troquelado específico. No solo el cuerpo está estructurado de forma distinta, no solo son distintas algunas de la funciones fisiológicas, sino que toda la vida corporal es distinta, la relación de cuerpo y alma es distinta, y dentro de lo anímico, la relación de espíritu y sensibilidad, así como la relación de las fuerzas espirituales entre sí. A la especie femenina le corresponde la unidad y clausura de toda la personalidad corpóreo-anímica, el armónico desarrollo de las energías; a la especie masculina, el crecimiento de algunas energías en orden a actividades muy intensas" ${ }^{20}$. Resalta la corporeidad que en cuanto totalidad de una relación constituyente de cuerpo y alma en cuanto distinta entre varón y mujer y que en la mujer carga hacia la unidad y clausura de toda la personalidad corpórea anímica.

Sintetizando: en un primer acercamiento, la especificidad de la mujer emerge por medio de una metodología apta para abordar la cuestión y que como tal se revela como esfuerzo fenomenológico, entrelazado con la ontología y capaz de distinguir lo específico e irrepetible en lo común de todo cuanto existe. Tal método parte del sujeto, pero involucra la alteridad, fenómeno constituyente y misterioso, que requiere de la empatía para comprender la especificidad de la mujer.

\section{b. La empatía y su relevancia para la cuestión de la mujer como misterio de alte- ridad}

Edith Stein comprende la empatía en estrecha interrelación con la alteridad $^{21}$, cuyo misterio constituye una noción clave en el pensamiento steiniano, no del todo dilucidado, pese a los esfuerzos realizados ${ }^{22}$. Pues

${ }^{20}$ La mujer 228 F 167:Ich bin der Überzeugung, dass die Species Mensch sich als Doppel-Species"Mann" und "Frau" entfaltet, dass das Wesen des Menschen, an dem kein Zug hier und dort fehlen kann, auf zweifache Weise zur Ausprägung kommt, und dass der ganze Wesensbau die spezifische Prägung zeigt. Es ist nicht nur der Körper verschieden gebaut, es sind nicht nur einzelne physiologische Funtionen verschieden, sondern das ganze Leibesleben ist ein anderes, das Verhältnis von Seele und Leib ist ein anderes und innerhalb des Seelischen das Verhältnis von Geist und Sinnlichkeit, ebenso das Verhältnis der geistigen Kráfte zueinander. Der weiblichen Species entspricht Einheit und Geschlossenheit der gesamten leiblich-seelischen Persönlichkeit, harmonische Entfaltung der Kräfte; der männlichen Species Steigerung einzelner Kräfte zu Höchstleistungen.

21 T. van DER Driessche, L'Altérité, Fondement de la personne bumaine dans l'oeuvre d'Edith Stein, (Bibliotheca Ephemeridum Theologicarum Lovanaienneisum, 212) LeuvenParis-Dudley, MA 2008, 275-76.

22 Ibid 50. 
no puedo ser yo mismo sino por el otro. Fundamentalmente no puedo ser yo mismo más que por el otro, más que en el otro. Esta problemática de la relación con el otro atraviesa toda la obra de Edith Stein. Los escritos previos a su conversión explican la importancia del alter ego para la constitución de la persona humana, sacando a la luz un nexo misterioso entre universalidad, particularidad e individualidad.

La autora, de hecho, nos sitúa aquí ante un "anclaje originario en la realidad dada, para dejarla ser en el devenir: este devenir no es ningún otro principio que el principio de la individualidad como tal: darse afectivamente, para que este ser dado se dé, pero no como llamado formal -Marion-. Si la ciencia moderna no conoce individuos, sino solo estructuras, procesos o informaciones en su globalización objetiva, entonces, cabe recordar enfáticamente que no existe ningún tipo de conocimiento, si este no fuera primero individualizado". Con esto, Edith Stein plantea un desafío fundamental, que se parece a la inversión del árbol de Porfirio, invocada por Hans Urs von Balthasar, aunque esclarecida metodológicamente de modo diferente ${ }^{23}$.

La autora recapitula lo expuesto al respecto e insiste: "Hasta ahora hemos hablado siempre del yo puro como del sujeto del vivenciar carente de cualidades e indescriptible de otra manera. Hemos encontrado en los distintos autores -en Lipps- la concepción de que este yo no es un 'yo individual', sino que solo llega a serlo en contraste con el 'tú' y el 'él'. ¿Qué quiere decir esta individualidad? Ante todo, solo que él es 'él mismo’ y ningún otro. Esta 'mismidad' está vivenciada y es fundamento de todo aquello que es 'mío'. Naturalmente, se produce resalte frente a otro solo cuando otro está dado. Por lo tanto, este otro no se distingue cualitativamente de él -puesto que ambos son carentes de cualidad- sino solo por el hecho de que él es 'otro" 24 . La alteridad, innegablemente, fundante a nivel

23 H.Urs von Balthasar, Theodramatik II/1 189. Cf. A. Meis, "Razón y amor en la Teológica de Hans Urs von Balthasar", Teología y Vida 45(2004) 104-136

${ }^{24}$ Sobre la empatia 54- E. STEIN, Zum Problem der Einfühlung (=PE) (ESG 5/1) Freiburg-Basel-Wien 2008, 54:'Wir haben bisher immer vom reinen Ich als dem sonst unbeschreiblichen qualitätslosen Subjekt des Erlebens gesprochen. Wir haben bei verschiedenen Autoren-z.B.bei Lipps-die Auffassung gefunden, dass die ich kein "individuelles", sei, sondern es erst werde im Gegensatz um "Du" und "Er" (29). Was besagt diese Individualität? Zunächst nur, dass es "es selbst" ist und kein anderes. Diese "Selbstheit" ist erlebt und Fundament alles dessen, was "mein" ist. Zur Abhebung gegenüber einem anderen kommt es natürlich erst, wenn ein anderes gegeben ist. Dieses ist von ihm zunächst nicht qualitativ unterschieden - da ja beide qualitätslos sind-, sondern nur dadurch, dass es eben ein "anderes" ist. 
del yo puro, no revela todavía su peculiaridad propia, lo cual requiere de un paso más en la comprensión del modo de manifestarse ella.

Por eso, Edith Stein continúa: "Y esta alteridad se manifiesta en el modo de darse; él se muestra como otro respecto a mí en tanto que me está dado de otra manera que 'yo': por eso es un 'tú'; pero se vivencia tal como yo me vivencio, y por eso es el 'tú' un 'otro yo'. De esta manera, el yo no experimenta una individualización en tanto que otro le está enfrente, sino que su individualidad o, por decirlo mejor (porque aún debemos reservar la designación 'individualidad' para algo distinto), su mismidad, se resalta frente a la alteridad del otro" 25 . Para la autora, la mismidad del yo es entonces decisiva frente al otro. Pero cambos se oponen o se interrelacionan? ¿Cómo?

Edith Stein explica, hablando de la "corriente de la conciencia": "Frente a la 'misma' corriente de conciencia comparecen entonces 'otras' corrientes de conciencia, frente a la del 'yo', las del 'tú' y 'él'. Su mismidad y alteridad se fundan en la del sujeto al que pertenecen; pero no solamente son "otras", sino también "diferentes", porque cada una tiene su contenido vivencial peculiar. Dado que cada vivencia singular de una corriente está caracterizada especialmente por su posición en el conjunto de la conexión de vivencias, por ello está también caracterizada así, además de su pertenencia al yo, cual vivencia de este y de ningún otro yo, por tanto también cualitativamente. Las corrientes de conciencia, pues, están cualitativamente diferenciadas en virtud de su contenido vivencial" ${ }^{\prime 26}$. Esta diferenciación, entonces, es constituyente de la especificidad de cada uno y

25 Sobre la empatía 54. PE 54: Und diese Andersheit bekundet sich in der Art der Gegebenheit; es erweist sich als ein anderes als ich, indem es mir anders gegeben ist als "ich": darum ist es "Du"; aber es erlebt sich so, wie ich mich erlebe, und darum ist das "Du" ein "anderes Ich". So erfährt das ich keine Individualisierung, indem ihm ein anderes gegenübertritt, sondern seine Individualität, oder, wie wir lieber sagen wollen,(weil wir die Bezeichnung "Individualität” noch für etwas aufsparen müssen) seine Selbstheit kommt zur Abhebung gegenüber der Andersheit des andern.

26 Sobre la empatía 55. PE 55: Dem "selben" Bewusstseinsstrom treten nun "andere" Bewusstseinsströme gegenüber, dem des "Ich" die des "Du" und "Er". Ihre Selbstheit und Andersheit gründet sich auf die des Subjekts, dem sie zugehören; sie sind aber nicht "andere", sondern auch "verschiedene", da jeder seinen eigentümlichen Erlebnisgehalt hat. Da jedes einzelne Erlebnis eines Stromes durch seine Stellung im gesamten Erlebniszusammenhang besonders charakterisiert ist, so ist es dadurch auch ausser seiner Ichzugehörigkeit, also auch qualitativ, als Erlebnis dieses und keines anderen Ich gekennzeichnet.Vermöge ihres Erlebnisgehaltes sind also Bewusstseinsströme qualitativ unterschieden. 
nos permite vislumbrar la especificidad de la mujer. Pero cabe preguntarse: ¿el contenido vivencial del yo entra en el tú y viceversa? $O$ ¿no persiste más bien el misterio, que como tal es constituyente? En estas preguntas se comienza a perfilar con mayor certeza la especificidad de la mujer.

Sintetizando, puede apreciarse que la empatía permite abrir el yo al otro, y el otro entra en el yo. Pero ¿qué es lo que entra?, ¿el otro, su ser, sus sentimientos? De hecho, no experimentamos los sentimientos ajenos en cuanto contenido, sino solo podemos establecer su semejanza con lo que vivenciamos, es decir, un nexo misterioso entre lo mío y lo otro del otro, quien es sujeto como yo, pero quien, con una interioridad diferenciada a la mía, remite al Gemüt

\section{c. El Gemüt}

Cuando en el contexto del problema de la empatía la autora analiza "el alma", advierte: "En la intensidad de nuestros sentimientos se delata la pasionalidad; en la facilidad con la que ellos aparecen, la convulsibilidad de nuestro ánimo-Gemüt ${ }^{27}$. Y prosigue, pese a que lo considera innecesario ${ }^{28}$, afirmando: "En tanto que los fenómenos de expresión aparecen como afluencia de los sentimientos son, a la vez, expresión de las propiedades anímicas que en ellos se manifiestan: la mirada rabiosa, por ejemplo, delata un temperamento fuerte, un Gemütsart ${ }^{29}$. Edith Stein concibe, entonces, la posibilidad de expresiones diversas del alma común en cada individuo, lo cual resulta relevante cuando se trata de la especificidad del alma femenina.

La autora aborda este dato detenidamente en su obra temprana, pero editada póstumamente, "Potencia y Acto"30, cuando explica el Gemüt en un denso párrafo, dedicado exclusivamente a dicho concepto, pero en

27 Sobre la empatía 56 PE 56: In der Intensität unserer Gefühle verrät sich die Leidenschaftlichkeit in der Leichtigkeit, mit der sie sich einstellen, die Aufwühlbarkeit unseres Gemütes usw.

28 Sobre la empatía 56: PE 56: Es erübrigt sich, diesen Beziehungen weiter nachzugehen.

29 Sobre la empatía 72: PE 71s: Indem die Ausdrucksphänomene als Ausfluss der Gefühle erscheinen, sind sie zugleich Ausdruck der sich in ihnen bekundenden seelischen Eigenschaften: der wütende Blick z.B. verrät eine heftige Gemütsart.

30 E. Stein, Poternz und Akt. Studien zu einer Philosophie des Seins. Eingeführt und bearbeitet von Hans Rainer Sepp (ESG 10/2) Freiburg 2005, 279 pp. (PA). 
interrelación con otras nociones ${ }^{31}$. Afirma: "El acto puro, así lo veíamos, es ser, este ser es un conocer perfecto y completo, es la voluntad creadora y la adhesión a sí mismo (y también a todo lo creado) en la forma máxima de la adhesión, del amor. En los espíritus creados entra todo lo que aquí es unidad de un acto, se separa en una serie de actos y potencias real y temporalmente separados, pero que están en un contexto determinadamente ordenado. Bajo el término 'intelecto' entendemos todos los actos reales y posibles juntos, que están dirigidos al conocimiento del ente y en los que es adquirido conocimiento del ente; bajo el término 'voluntad' entendemos todos los actos, a través de los cuales algo que no es captado todavía como real, pero es posible captarlo, está determinado al ser y eventualmente (por medio de una acción dirigida por la voluntad) a ser puesto en la existencia"32. Resalta aquí la relevancia del elemento intelectivo y volitivo como constitutivos del Gemüt, cuya interrelación luego se precisa.

Pues Edith Stein afirma: "Entre la recepción del mundo con el intelecto y de la configuración del mundo por la voluntad está la interior confrontación de la persona con el mundo en el ánimo-Gemüt. Por regla general, el encuentro del sujeto espiritual con un objeto no es algo simplemente racional, no es simple recibir cognoscitivo, así se es interiormente tocado e impulsado a una toma de posición. El toque es opuestamente caracterizado: como placer o desagrado ${ }^{33}$, las correspondientes tomas de posición como consentimiento o rechazo, y en su forma extrema como

31 PA 363-365. (ESG 10/2): 118-120. C. Das Gemüt.

32 PA 118: Der actus purus, so sahen wir, ist Sein, ist dieses Sein vollkommen umfassendes Erkennen, ist schöpferischer Wille und Zustimmung zu sich selbst (und auch zu allem Geschaffenen) in der höchsten Form der Zustimmung, der Liebe. In den geschafffenen Geistern tritt all das, was hier Einheti eines Aktes ist, auseinander in eine Reihe sachlich und zeitlich getrennter Akte und Potenzen, die aber in einem bestimmt geordneten Zusammenhang stehen. Unter dem Titel "Verstand" fassen wir alle wirklichen und möglichen Akte zusammen, die auf Erkenntnis von Seiendem gerichtet sind und in denen Erkenntnisse von Seiendem gewonnen wird; unter dem Titel "Willen" alle Akte, durch die etwas, was als noch nicht wirklich, aber möglich erfasst ist, zum Sein bestimmt und evtl. (vermittels eines durch das Wollen eingeleiteten Tuns) ins Dasein gesetzt wird.

33 Nota 82: Es una cuestión discutida si hay un medio entre los extremos, un "adiaphoron", esto sería un encuentro sin un ser impactado íntimamente. En apariencia se da sin duda alguna. Quizá el asunto se podría aclarar en el sentido de que cada encuentro está apropiado para impactar interiormente, pero el sujeto no siempre está en disposición de ser impactado. 
amor y odio. Esta polaridad se manifiesta no solo en el encuentro de la persona con otros, como ella misma es, sino también en su ser consigo misma ('encuentro' consigo misma no sería acertado para las circunstancias ordinarias, sino solo para las formas completamente especiales de la objetivación del yo)"34. Emerge así una significativa polaridad de la toma de posición, hacia el otro y para consigo misma, la cual será decisiva para poder comprender el Gemüt en cuanto especificidad de la mujer.

En efecto, la autora recuerda: "Hemos caracterizado el ser espiritual según el lado intelectual como ser abierto y ser transparente. Este ser transparente como ser-consciente-de-sí mismo no es simplemente una conciencia del propio ser, sino también de lo que el ente, la persona, es y cómo es en cada caso. La conciencia de lo que soy y sé cómo soy no es un conocimiento racional. El 'quid' no es todavía unívoco. Puede significar: lo que soy 'del todo personalmente', un individuo simplemente único ${ }^{35}$. Lo que soy, según mi esencia general, de esto puedo tener conocimiento en un amplio trabajo intelectual, esto es, conseguir conocimiento comprensible en conceptos generales y palabras. Pero la conciencia inmediata de mí mismo no es este conocimiento, sino solo uno de los puntos de partida para llegar a dicho conocimiento. Lo que soy como individuo espiritual, no es generalmente accesible a ningún conocimiento racional (en un sentido que acabamos de establecer). En cuanto cosa simplemente única el individuo no puede ser reconducido a conceptos universales, a lo que puede ser llamado con un nombre propio. Pero por eso no completamente incognoscible y no conocido. Lo que yo soy, o yo con lo que soy, soy para mí (y también para los demás en cierta manera). Este quid se encuentra en un cómo. Estoy en cada momento en una determinada actualidad, inclinado a ese o aquel objeto, pero a la vez me 'siento dispuesto

34 PA 118s: Zwischen der Aufnahme der Welt mit dem Verstand und der Gestaltung der Welt durch den Willen steht die innere Auseinandersetzung der Person mit der Welt im Gemüt. In der Regel ist die Begnung des geistigen Subjekts mit einem Objekt keine bloss verstandesmässige, kein blosses erkenntnismässiges Aufnehmen- es wird dadurch innerlich berührt und zu einer Stellungnahme aufgefordert. Die Berührung ist gegensätzlich charakerisiert: als Lust oder Unlust (Note 1), die entsprechenden Stellungnahmen als Zustimmung oder Ablehnung, in deren höchster Form als Liebe oder Hass. Diese Polarität zeigt sich nicht nur in der Begegnung der Person mit anderm, als sie selbst ist, sondern auch in ihrem Sein mit sich selbst ("Begegnung" mit sich selbst wäre fur den duchschnittlichen Tatbestand nicht zutreffend, sondern nur für ganz besondere Formen der Verständlichung des Ich).

35 Advierte la autora en la Nota 83: la cuestión de la individualidad de la persona será tratada en principio en las pp. 516-517. 
emotivamente' de esta manera y otra" ${ }^{36}$. Aquí se abre la posibilidad cada vez más transparente para el ser propio "mujer", es decir, un "cómo" ser y expresarse, de modo permanente, por un "estado de ánimo”, el Gemüt.

Esto explica Edith Stein, más detalladamente, cuando afirma: "El 'estado de ánimo' -Gemüt- es la disposición interior presente: así estoy al presente, en base a lo que soy y de lo que siempre me toca interiormente. El "sentir" es la conciencia de este estado de ánimo-Gemüt. El quid está solo en el cambio del cómo (aquello de que está determinado tiene su matiz individual) y en el cambio de todo lo exterior que viene a mi encuentro, que está duraderamente presente. Yo soy duraderamente (aunque no inmutable en lo duradero) en un estado de ánimo -Gemüt- por lo que soy cambiante a través de lo que viene a mi encuentro; sentirse desde dentro en un estado de ánimo -Gemüt-, esto es estar tocado por sí mismo. Si es placentero, entonces estoy conmigo mismo en concordancia, en tranquilidad y paz; la toma de posición, que es motivada por ello es asentamiento, amor a sí mismo. Si es desagradable, entonces estoy por eso impulsado al rechazo de mí mismo, a la huida de mí mismo, al odio de mí mismo"37.

36 PA 119: Wir haben das geistige Sein nach der intellektuellen Seite charakterisiert als Geöffnetsein und Durchleuchtetsein. Dieses Durchleuchtetsein als Selbst-bewusstSein ist nicht bloss ein Bewusssein des eigenen Seins, sondern auch dessen, was das Seiende, die Person, ist und wie es jeweils ist. Das Bewusssein dessen, was ich bin und wie ich bin, ist keine rationale Erkenntnis. Das "Was" ist noch nicht eindeutig. Es kann heissen: was eine geistige Person überhaupt ist, also etwas Allgemeines; oder was ich "ganz persönlich" bin-ein Individuelles, schlechthin Einmaliges. (Note1) Was ich meinem allgemeinen Wesen nach bin, davon kann ich in langer Verstandesarbeit eine gewisse rationale, das will sagen, in allgemeine Begriffe und Worte fassbare Erkenntnis gewinnen. Aber das inmittlebare Bewusstsein meiner selbst ist nicht diese Erkenntnis, sondern nur einer der Ausgangspunkte, um dahin zu gelangen. Was ich als geistiges Individuum bin, das ist überhaupt keiner rationalen Erkenntnis ( im eben festgelegtn Sinn) zugänglich. Es kann als ein schlechhin einmaliges nich auf allgemeine Begriffe gebracht, es kann höchstens mit einem Eigennamen benannt werden. Es ist aber darum nicht vollkommen unerkennbar und unerkannt. Was ich bin, oder ich mit dem, was ich bin, bin(ich) für mich(und auch für andere) in einer gewissen Weise. Das Was steckt dabei in einem Wie. Ich bin in jedem Augenblick in einer bestimmten Aktualität, bin darin dem oder jenem Gegenständlichen zugewendet, zugleich aber "fühle" ich mich so oder so "gestimmt".

37 PA 119: Die "Stimmung" ist die gegenwärtige innere Verfassung: So bin ich gegenwärtig-auf Grund dessen, was ich bin, und dessen, was mich eben innerlich berührt. Das "Fühlen" ist das Bewusssein dieser Stimmung. Das Was ist nur im Wechsel des Wie alles Äusseren, das mir begnet, dauernd gegenwärtig. Ich bin dauernd (wenn auch nicht unwandelbar dauernd) gestimmt durch das, was ich bin, und wechselnd durch das, was mir begegnet.Von innen sich gestimmt fühlen, d.h. von sich selbst 
La variabilidad del "estado de ánimo" atestigua una dimensión valórica, que la autora todavía aborda con mayor precisión.

Señala, pues, "Agrado o desagrado en el propio ser (en el quid y en el hecho de que) muestran algo de positivo o negativo en el ente mismo, en un bonum o malum (con esto no se dice que el testimonio sea infalible. Pero se descubren aquí las conexiones entre el ente, el valor, esto es, el ente valioso y la manifestación de lo valioso en el ánimo-Gemüt. En qué estado de ánimo-Gemüt estoy, esto viene en primer lugar de dentro y me dice algo de lo que soy y como yo estoy interiormente. Pero de ordinario viene también de fuera, y yo estoy consciente de que he sido tocado interiormente por esto o aquello, de esta o aquella manera. Agrado y desagrado (en los múltiples grados cuantitativos y cualitativos) son los caracteres inmediatos del contacto"38. Tal análisis de la dimensión interior y exterior del Gemüt, sin duda, permite apreciar una modulación del estado de ánimo pertinente a lo que le sucede, preferentemente a la mujer, sin que Edith Stein pretenda negar semejantes reacciones en el varón.

En efecto, prosigue: "En base a este contacto veo los objetos provistos con las cualidades correspondientes -cualidades de valor- y me vuelvo a ellos con ciertas tomas de posición, afirmo o niego su ser, me alegro de ellas y me veo inclinado a ellas o tengo horror y soy rechazado. De ahí brota una variada conducta respecto a una voluntad a una acción voluntaria: busco los objetos o los evito, los dejo o los conservo como son, o trato de cambiarlos, y si no, los destruyo. Todo esto son formas de enfrentamiento de la persona con aquello que le viene al encuentro y que en el agrado o desagrado del contacto el entendimiento no solo roza

berührt sein. Ist es lustvoll, so bin ich mit mir selbst im Einklang, in Ruhe und Frieden; die Stellungnahme, die dadurch motiviert ist, ist Zustimmung, Selbstliebe. Ist es unlustvoll, so werde ich dadurch zur Ablehnung meiner selbst, zur Flucht vor mir selbst, zum Selbshass getrieben.

38 PA 119s: Lust und Unlust am eigenen Sein (am Was und am Dass) weisen auf ein Positives oder Negatives im Seienden selbst, auf ein bonum oder malum (Es ist damit nicht gesagt, dass das Zeugnis ein untrügliches sei. Es enthüllen sich aber hier die Zusammenhänge zwischen dem Seienden (ens), dem Wert bzw. Dem wertvollen Seienden (bonum) und der Bekundung des Wertvollen im Gemüt) Wie isch gestimmt bin, das kommt einmal von innen her und sagt mir etwas davon, was und wie ich innerlich bin. Es kommt aber in der Regel auch von aussen her, und ich bin mir zumeist dessen bewusst, dass ich von dem und jenem innerlich so oder so berührt werde."Lust" und "Unlust" (in den mannigfachsten quantitativen und qualitativn Abstufungen) sind die unmittelbaren Charaktere der Berührung. 
superficialmente, sino con mayor o menor profundidad impacta interiormente: promoviendo y aumentando o disminuyendo su ser" 39 .

"Lo más fuerte es el ser impactado interiormente y por eso también la confrontación, si el ente con que uno se encuentra igualmente es una persona. Aquí el asentimiento y el rechazo reciben la forma de amor y de odio" $"$. No cabe duda de que con destacar el ser persona, la autora se acerca, en forma definitiva a cómo ella explicará la especificidad de la mujer, es decir, "La fuerza de la mujer reside en su vida del Gemüt", mientras "El empeño del varón se dirige preferentemente a realizarse por medio del conocimiento y la actuación”. Antes de seguir, sin embargo, con el análisis, cabe detenerse en una breve recapitulación de los elementos descubiertos por una primera aproximación metodológica a la especificidad de la mujer para luego fijarse en el arquetipo trinitario desde el cual recién se proyecta una respuesta válida concreta a la cuestión planteada.

Recapitulando, se puede afirmar que Edith Stein sostiene la diferencia entre la actitud fundamental del alma de la mujer y la del varón diferencia que se debe al hecho de que la mujer vive mucho más que el varón en el Gemüt. Aunque las potencias del alma-razón, Gemüt y voluntad son comunes al varón y a la mujer, no existe, sin embargo, igualdad en el modo como se distribuyen y desarrollan estas potencias en cada uno. Si bien este primer esclarecimiento de la cuestión es fruto del análisis filosófico fenomenológico ontológico, los resultados no son ajenos a lo que la teología enseña. Sin embargo, según la autora, la teología no pregunta como la filosofía: "¿Es la diferenciación algo necesario o contingente?”, sino que dice: "Dios creó al ser humano a su imagen. Hombre y mujer los creó", lo cual significa que "ahí está manifestado el hecho de la unidad y el he-

39 PA 120: Auf Grund dieser Berührung sehe ich die Gegenstände mit entsprechenden Qualitäten-Wertqualitäten-ausgestattet und wende mich mit gewissen Stellungnahmen ihnen zu, bejahe oder verneine ihr Sein, freue mich an ihnen und fühle mich zu ihnen hingezogen oder habe Abscheu und werde abgestossen. Daraus entspringt ein mannigfaches willensmässiges Verhalten und willentliches Tun: Ich suche die Gegenstände auf oder fliehe sie, lasse und bewahre sie, wie sie sind, oder such sie abzuändern, wo nicht gar zu vernichten. All das sind Formen der "Auseinandersetzung" der Person mit dem, was ihr begegnet und sie in der Lust oder Unlust der Berührung nicht nur oberflächlich streift, sondern mehr oder minder tief innerlich ergreift: ihr Sein fördernd und steigernd oder mindernd und bedrohend.

40 PA 120 Am stärksten ist das innere Ergriffenwerden und darum auch die Auseinandersetzung, wenn das Seiende, dem man begegnet, selbst eine Person ist. Hier nehmen Zustimmung oder Ablehnung die Form von Liebe und Hass an. 
cho de la diferenciación". Pero, para Edith Stein, esto "es una expresión lapidaria que pide explicación ¿Qué significa la imagen de Dios en el ser humano?" y que siempre la pedirá ${ }^{41}$. Entonces, nos preguntamos: ¿cuál es la interrelación de la afirmación de la Sagrada Escritura con la especificidad de la mujer encontrada gracias a las posibilidades eidéticas del análisis filosófico? Para responder a esta pregunta nos debemos acercar al origen fundante de la especificidad de la mujer, el misterio de la Trinidad.

\section{El origen fundante trinitario de la especificidad femenina}

La cuestión de la especificidad de la mujer, efectivamente, remite a la pregunta por el fundamento último de tal especificidad, es decir, por el ser de todo cuanto existe y su origen, tal como este se trasluce en el espíritu creado. Afirma, pues, la autora: "Si a los seres humanos no les dispuso en el mundo como especie única, sino doble, también a su existencia debe pertenecerles, junto a uno común, un sentido diferente" ${ }^{\text {"42. Y }}$ prosigue, "San Agustín y santo Tomás y la tradición subsiguiente vieron en el espíritu del ser humano la imagen de la Trinidad". Esto "se entiende de diversas maneras, pero sobre todo de forma que en el ser, en el conocer y en el amar están transmitidos Padre, Hijo y Espíritu Santo"43. Para acceder fundadamente a esta imagen trinitaria, nuestro conocimiento requiere de la vía de analogia entis, en cuanto solo ella puede dilucidar la existencia de las tres hipóstasis en Dios y dentro de ellas la peculiar interrelación del ser personal del Espíritu Santo con respecto a la especificidad de la mujer, que Edith Stein sostiene ${ }^{44}$.

41 La mujer 126-127. F 105: Wenn er den Menschen nicht als einfache, sondern als zweifache Spezies in die Welt hineinstellte, so muss auch ihrem Dasein neben einem gemeinsamen ein verschiedener Sinn zukommen.

42 F 105: Agustín und Thomas und die ihnen folgende Tradition sahen im Menschengeist das Abbild der Trinität. Es wird verschieden gefasst, aber vornehmlich so, dass in Sein, Erkennen und Liebe Vater, Sohn und Geist wiedergegeben sind.

43 F 105: Wenn im Sohn die göttliche Weisheit Person geworden ist, im Geist die Liebewenn auf der anderen Seite in der männlichen Natur der Verstand vorherrschend ist, in der Frau das Gemüt, so versteht man es, dass immer wieder der Versuch gemacht wird, die weibliche Natur in eine besondere Verbindung mit dem Hl.Geist zu bringen.

44 EES 60: Oder wäre das Kind "vernünftig", das beständig in der Angst lebte, die Mutter könnte es fallen lassen? Ich stosse also in meinem Sein auf ein anderes, das nicht meines ist, sondern Halt und Grund meines in sich haltlosen und grundlosen Seins, auf den ich in mir selbst stosse, das ewige Sein zu erkennen. Das eine ist der Weg des Glaubens: wenn Gott sich offenbart als "der Seiende", als "Schöpfer" und "Erhalter", 


\section{a. La analogia entis y la imagen de la Trinidad}

Para verificar la imagen de la Trinidad en el espíritu humano Edith Stein emprende la vía de la analogia entis, con aquel recurso a una racionalidad propia de la teología, basada en la experiencia humana inteligible y sentida a la vez, que caracteriza a esta pensadora, profundamente convencida de que la verdad existe. Comenta ella así: "En efecto, el niño que viviera constantemente en la angustia de que su madre le dejara caer, ¿sería razonable? En mi ser yo me encuentro entonces con otro ser que no es el mío, sino que es el sostén y el fundamento de mi ser que no posee en sí mismo ni sostén ni fundamento. Puedo llegar por dos vías a ese fundamento que encuentro dentro de mí mismo a fin de conocer al ser eterno. La primera es la de la fe. Si Dios se revela como el ente, como el creador y el conservador, y si el Salvador dice: "Aquel que cree en el Hijo tiene la vida eterna (Jn 3, 36), estas son respuestas claras a la cuestión enigmática que concierne a mi propio ser. Y si Dios me dice por la boca del profeta que me es más fiel que mi padre y mi madre, y que Él es el amor mismo, reconozco cuán razonable es mi confianza en el brazo que me sostiene y cómo toda angustia de caer en la nada es insensata, mientras yo no me desprenda por mí mismo del brazo protector..." 45 .

Advierte Edith Stein: "Es posible también que mi ser fugaz tenga un sostén en alguna cosa finita. Pero un finito no podría ser el sostén ni el fundamento último. Toda cosa temporal en cuanto tal es fugaz y ella misma tiene necesidad de un sostén eterno. Si yo estoy ligado a otro ser finito

und wenn der Erlöser sagt: "Wer an den Sohn glaubt, der hat das ewige Leben", so sind das lauter klare Antworten auf die Rätselfrage meines eigenen Seins. Und wenn Er mir durch den Mund des Propheten sagt, dass Er treuer als Vater und Mutter zu mir stehe, ja dass Er die Liebe selbst sei, dann sehe ich ein, wie"vernünftig" mein Vertrauen auf den Arm ist, der mich hält, und wie töricht alle Angst vor dem Sturz ins Nichts-wenn ich mich nicht selbst aus dem bergenden Arm losreisse.

45 EES 60: Es mag sein, dass mein flüchtiges Sein einen "Halt" hat an etwas endliches. Aber als Endliches könnte das nicht der letzte Halt und Grund sein. Alles Zeitliche ist als solches flüchtig und bedarf des ewigen Haltes (Note 54) Bin ich mit meinem Sein an anderes Endliches gebunden, so werde ich mit ibm im Sein erhalten. Die Seinssicherheit, die ich in meinem flüchtigen Sein spüre, weist auf eine inmittelbare Verankerung in dem letzten Halt und Grund meines Seins (unbeschadet möglicher mittelbarer Stützen) hin. Das ist freilich ein sehr dunkles Erspüren, kaum "Erkenntnis" zu nennen. Augustinus, der den Weg zu Gott vor allem vom inneren Sein her gesucht und das Hinausweisen unseres Seins über sich selbst zum wahren Sein in immer neuen Wendungen betont hat, bringt doch zugleich stets unser Unvermögen, den Unfasslichen zu fassen, zum Ausdruck. 
con mi ser, entonces yo estoy conservado en el ser con él. La seguridad de ser que yo siento en mi ser fugaz indica una estabilidad inmediata en este sostén y este fundamento último de mi ser (a pesar de sostenes indirectos eventuales). Esto significa seguramente una percepción muy oscura que apenas es posible llamar conocimiento: San Agustín, quien buscó el camino de Dios sobre todo a partir del ser interior y quien indicó en frases siempre nuevas el empuje de nuestro ser más allá de sí mismo hacia el ser verdadero, expresa, al mismo tiempo y de muchas maneras, nuestra impotencia para captar lo inasible" ${ }^{\prime 4}$. La certeza inasible que emerge aquí sin embargo, se deja captar a nivel ontológico por medio de los trascendentales.

Esto lleva a Edith Stein a prestar una atención especial a dichos "vestigios del ser", que explicitan diferencias definibles en la unidad del mismo ser, es decir, el ser trasluce en el verum, bonum, pulchrum sin que se agote en tales vestigios, sino más bien los desborda. Así lo constata la autora al delimitar su investigación sobre el "sentido del ser" ${ }^{47}$. Pregunta: “¿El sentido del ser ha sido agotado por lo que creemos haber encontrado como significado común de todo ser verdadero: -ser como despliegue, que sin embargo es otro nombre, no es una explicación o una reduccióny se trata de un sentido pleno o solamente de la forma de una plenitud que recibe un llenado distinto por diferentes modos de ser? A la primera pregunta encontraremos una respuesta si nos acordamos de lo que ya hemos puesto en evidencia acerca del sentido del ser cuando hemos examinado cada una de las determinaciones trascendentales" ${ }^{\prime 4}$.

46 EES 280ss.

47 SFE 930 EES 285: Ist der Sinn des Seins mit dem, was wir als gemeinsamen Sinnbestand in allem wahren Sein gefunden zu haben glauben-Sein als "Entfaltung", was aber nur ein anderer Name, keine Erklärung oder Zurückführung ist- erschöpft und ist dies ein "voller Sinn" oder nur die Form einer Fülle, die durch die verschiedenen Seinsweisen eine verschiedene Ausfüllung erfährt? Auf die erste Frage werden wir die Antwort finden, wenn wir uns das vergengenwärtigen, was schon bei der Erörterung der einzelnen transzendentalen Bestimmungen über den Sinn allen Seins herausgestellt wurde.

48 SFE 931 EES 285: Sein als Entfaltung eines Was bedeutet nicht nur das Auseinander und Ineinander dessen, was in diesem Was enthalten ist, sondern zugleich sein Offenbarsein (bzw.-werden) oder Fassbarsein für einen erkennenden Geist (d.h.alles Sein ist als solches wahres Sein); es bedeutet: seinen Platz in der Gesamtheit alles Seienden einnehmen und damit zu der Vollkommenheit dieses Ganzen beitragen( d.h.gut sein); es bedeutet: nach einem bestimmten Aufbaugesetz geordnet sein und dadurch sowohl mit dem ordnenden als mit dem in einer entsprechenden Ordnung 
Por eso, la autora explica: "Ser, en cuanto despliegue de un quid, no solo significa separar y unir lo que está contenido en este quid, sino al mismo tiempo su ser manifiesto (su devenir manifiesto) o su ser captable por un espíritu cognoscente (es decir, todo ser en cuanto tal ser verdadero); esto significa: tomar su lugar en la totalidad de todo ente y por consiguiente contribuir a la perfección de este todo (es decir, ser bueno); significa igualmente: estar ordenado según una ley estructural determinada y así encontrarse en un orden correspondiente, es decir, ser bello y al mismo tiempo ser racional. Cuando se habla de la unión y del orden de las partes de un todo se expresa también el hecho de que el ser uno pertenece al ser. Ahí donde el quid es un elemento simple, el significado de separar y unir, así como el orden de "partes" en el "todo" se restringe a la contraposición de "forma" y de "plenitud", tal como lo indica la estructura fundamental del ente: indica algo que es. La unidad tiene su lugar en el algo y en el ser, y gracias a los dos se alcanza la plenitud"49. Entonces, "unidad, verdad, bondad, belleza pertenecen al significado del ser mismo; y además conviene agregar que se trata del ser de algo y, específicamente, de un algo pleno" ${ }^{20}$. Aquí se patentiza, sin duda, aquella estructura óntica de la

erkennenden Geist in Einklang sein (d.h. schön sein und zugleich vernünftig sein). Wenn vom Ineinander und von der Ordnung der Teile eines Ganzen die Rede ist, so ist darin ferner eingeschlossen, dass zum Sein Einssein gehört. Wo das Was ein Einfaches ist, da schränkt sich die Bedeutung von Auseinander und Ineinander und die Ordnung der "Teile" im "Ganzen" ein auf den Gegensatz von "Form” und "Fülle”, wie ihn der Grundaufbau des Seienden: etwas, was ist, andeutet. Die Einheit hat im Etwas und im Sein ihre Stelle, durch beide ist die Fülle zusammengeschlossen.

49 SFE 931 EES 285:Einheit, Wahrheit, Gutheit, Schönheit gehören zum Sinnbestand des Seins selbst; und es gehört dazu, dass es Sein eines Etwas-und zwar eines erfüllten Etwas-ist.

50 SFE 934 EES 288: Wir haben das erste Sein" reines Sein" genannt und werden das jetzt vielleicht noch etwas besser verstehen können.Es wurde "rein" genannt, weil in ihm nichts von Nichtsein ist wie bei dem zeitlich Begrenzten, das einmal war und einmal nicht sein wird, und bei dem sachlich Begrenzten, das etwas und nicht alles ist. Weil es bei ihm keinen Übergang von der Möglichkeit zur Wirklichkeit gibt, keinen Gegensatz von Potenz und Akt, wurde es auch "reiner Akt" genannt. All das aber- die zeitliche und sachliche Unbegrenztheit wie die unwandelbare Seinsvollendung (die der Name "reiner Akt" ausdrückt)-weist hin auf jene so schwer fassbare Auszeichnung des Ewigen und Unendlichen: dass bei ihm nicht mehr-wie bei allem Endlichen-Sein und Seienden zu trennen sind. Es wird wohl auch das "erste Seiende" (primum ens) genannt). Aber das "ens"-wie alle transzendentalen Namen-gilt von ihm nur in einem analogen Sinn, ja hier ist die eigentliche Stelle der "analogia entis": des eigentümlichen Verhältnisses von endlichem und ewigem Sein, das es gestattet, auf Grund eines gemeinsamen Sinnbestandes hier und dort von "Sein" zu sprechen. 
especificidad de la mujer, que tiene en común el ser con el varón, a la vez que se plasma como un "algo" distinto.

Pero Edith Stein no se contenta con esta constatación, sino avanza hacia el "ser primero". Recuerda, por eso: "Hemos llamado al ser primero 'ser puro' y nos será tal vez posible ahora comprender un poco mejor tal expresión. El ser primero se llama 'puro' porque no hay en él nada de noser como en los limitados temporalmente, que una vez era y otra vez no será, y como en los limitados según objeto, que es algo y no es todo. Puesto que no hay en él ningún paso de la posibilidad a la realidad, ninguna contraposición de potencia y de acto, fue denominado también 'acto puro'. Pero el no ser limitado ni en tiempo ni en espacio, igual que la inmutable plenitud de ser (que expresa el nombre de 'acto puro'), indican esta característica tan difícil de concebir de lo eterno y de lo infinito: en este ser no se puede ya hacer separación entre el ser y el ente como en todo ser finito. También es llamado 'ente primero' (primum ens). Pero el 'ens' -lo mismo que todos los nombres trascendentales- vale solo en un sentido análogo; aquí se encuentra el lugar particular de la analogia entis: la relación peculiar del ser finito y del ser eterno que permite, fundándose en un significado común, hablar de 'ser' en los dos casos" 51 . Si aquí emerge el lugar particular de la analogia entis, cabe comprender la cuestión de la especificidad de la mujer a partir de este lugar crucial que la abre hacia Dios.

Pero advierte la autora: "Con todo se quiere decir que Dios se sitúa no solamente por encima de todas las categorías, sino también por encima de los trascendentales. En efecto, cuando expusimos cada una de las determinaciones transcendentales, el ser quedó como un residuo irreductible. Y cada determinación trascendental tenía en Dios otro significado diferente que en el ente finito: en el 'yo soy' están todas ellas prefiguradas

51 SFE 944 EES 296: Dami ist ausgesprochen, dass Gott nicht nur über die Kategorien, sondern auch über den Transzendentalien steht.Tatsächlich blieb ja bei der Behandlung jeder transzendentalen Bestimmung das Sein als ungelöster Test.Und jede hatte bei Gott eine andere Bedeutung als beim endlichen Seienden: im "Ich bin" sind sie alle ungeschieden vorgebildet [...] Das Verhältnis des göttlichen "ich bin” zur Mannigfaltigkeit des endlichen Seienden ist die urprüngliche analogia entis. Nur weil alles endliche Sein im göttlichen "ich bin" sein Urbild hat, hat alles einen gemeinsamen Sinn. Weil sich aber das Sein in der Schöpfung "teilt", hat das Sein nicht in allem Seienden streng denselben Sinn, sondern neben dem gemeinsamen einen verschiedenden Sinnbestand. Eben diese Teilung des Seins und den Sinn des endlichen Seins als Anteil am Einen Sein gilt es zu verstehen, soweit ein göttliches Geheimnis zu verstehen ist. 
sin separación... La relación del 'yo soy' divino con la diversidad del ente finito es la analogia entis más originaria. Solo porque todo ser finito tiene su arquetipo en el "yo soy" divino, todo tiene un significado común. Pero ya que el ser 'se divide' en la creación, el ser no posee en todo ente absolutamente el mismo sentido, sino al lado de un sentido común encontramos un significado diferente. Precisamente, conviene comprender esta división del ser y del sentido del ente finito como una participación de un ser único en la medida en que es posible comprender un misterio divino" 52 . Resalta no solo la índole analógica del ser común entre Dios y la criatura, sino también se desvela la unicidad del ser finito como fundado en el "yo soy" absoluto, de modo análogo.

Edith Stein, sin embargo, no se contenta con esta descripción relativamente evidente de la "analogia", sino la orienta hacia un quiebre más radical, cuando la circunscribe en cuanto relación de imágenes, que "exige una contraposición entre el ser eterno y el ser finito". De ahí que afirma que "el sentido de la creación en cuanto una a la existencia exige el inicio de un ser que no existía antes. Así la unidad del ser parece eliminada. Cuando Dios llama a la existencia a una cosa que no es él mismo, que posee un ser 'autónomo', entonces otro ser se encuentra claramente ya fuera del ser divino. ¿Cómo se puede entonces afirmar que todo ser es uno y que todo ser finito participa del uno? Esta proposición se justifica en el sentido de que no hay nada que sea originado por Dios, que no estuviera prefigurado en él, y que no se conservara en él ser por medio de él. La autonomía de lo creado no es ni comparable a la de la imagen en relación con el modelo o de la obra en relación con el artista. Es más bien la relación de la imagen quebrada con el objeto reflejado o del rayo reflejado con la luz no quebrada, la que puede servir de término de comparación. Pero tales imágenes siguen siendo imperfectas por designar algo sin

52 SFE 944 EES 297: Und der Sinn der Schöpfung als eines Ins-Dasein-rufens verlangt den Beginn eines Seins, das einmal nicht war. Damit scheint die Einheit des Seins aufgehoben. Wenn Gott etwas ins Dasein ruft, was nicht er selbst ist, was ein "selbständiges" Sein hat, so besteht offenbar ausser dem göttlichen Sein noch ein anderes.Wie ist es dann noch möglich zu behaupten, dass alles Sein eines sein und alles endliche Sein Anteil an dem einen? Diese Behauptung behält ihr Recht in dem Sinn, dass nichts ist, was nicht von Gott hervorgerufen, was nicht in ihm vorgebildet wäre und was nicht durch ihn einmal der des Bildes gegenüber dem Dargestellten oder des Werkes gegenüber dem Künstler an die Seite zu stellen. Eher liesse sich das Verhältinis des Spiegelbildes zum abgespiegelten Gegenstand oder des gebrochenen Strahles zum ungebrochenen Licht zum Vergleich heranziehen. Aber auch das sind unvollkommene Bilder für etwas, was ohnegleichen ist. 
equivalente" 53 . No cabe duda de que con tal constatación de un "quiebre" entre el ser finito y eterno, la cuestión de la especificidad de la mujer se salva de una proyección antropomorfa ingenua al interior del misterio de Dios, pese a la comunión de ser que Dios regala a su criatura.

En sintesis, puede constatarse que "lo creado no es una reproducción perfecta, sino solamente una 'imagen parcial', un 'rayo quebrado': Dios, el eterno, el Increado y el Infinito, no puede crear nada absolutamente semejante a sí mismo, puesto que no hay un segundo Eterno, Increado e Infinito" 54 . "Pues, aun la imagen reflejada por un espejo, por más estrechamente que esté unida con el objeto reflejado, constituye un ente diferente del objeto, pero Padre e Hijo son uno, 'un solo Dios y Señor"'. Sin embargo, la especificidad de la mujer se esclarece solo en cuanto "imagen”. Pero "Nos acercamos más al sentido dado aquí a la palabra 'imagen” cuando pensamos que Dios es Espíritu. No se ve en otro como es él mismo -como un retrato o un espejo-, sino en sí mismo" "55, Dios Padre, Hijo y Espíritu Santo. Esto nos lleva a auscultar más a fondo el significado de las hipóstasis divinas en cuanto ser arquetipo de la interioridad humana, que siente, conoce y ama.

\section{b. El ser hipóstasis del Padre-sentir-, Hijo- conocer-, Espiritu Santo- voluntad/ amor}

Edith Stein, al abordar la imagen de la Trinidad en la creación, consta-

53 EES 297 Es liegt im Sinn der Schöpfung, dass das Erschaffene kein vollkommenes Abbild sein kann, sondern nur ein "Teilbild", ein "gebrochener Strahl": Gott, der Ewige, Unerschaffene und Undendliche, kann nicht seinesgleichen erschaffen, weil es kein zweites Ewiges, Unerschaffenes und Unendliches geben kann. SFE 945. "Ahora nos resulta conveniente confrontar la relación del creador con la criatura y la del Padre con las otras personas divinas. En la profesión de fe de Atanasio, el Hijo se dice "engendrado, no creado". No entra en la existencia, es "igualmente eterno con el Padre". Forma con el Padre una sola esencia y, por ellos -puesto que en Dios ser y esencia coinciden- forma también un solo ser. No es una imagen parcial sino el todo. Es usual denominarle "imagen perfecta" del Padre. Pero conviene señalar que aquí el término "imagen” es también figurado.

54 SFE 945 EES 298: Denn selbst das Spiegelbild, so sehr es auch mit seinem Sein an den abgespiegelten Gegenstand gebunden ist, ist ein anderes Seiendes als der Gegenstand-Vater und Sohn aber sind eins, "ein Gott und Herr". Wir kommen dem, was hier mit "Bild" gemeint ist, am ehesten nahe, wenn wir daran denken, dass Gott Geist ist. Er schaut sich selbst nicht in einem anderen als er selbst ist-wie es ein gemaltes Bild oder der Spiegel ist,-sondern in sich selbst.

55 SFE 951 EES 303: Das Suche nach dem Sinn des Seins hat uns auf das Sein geführt, das Urheber und Urbild allen endlichen Seins ist. 
ta: "La búsqueda del sentido del ser nos ha conducido al ser que es autor y arquetipo de todo ser finito" 56 . Pues la autora argumenta: "Él se revela a nosotros como el ser en persona y más aún, como el ser en tres personas" y pregunta: "Si el Creador es el arquetipo de la creación, ¿no se debe encontrar en la creación una imagen, aunque lejana, de la unidad trinitaria del ser originario? Y por lo tanto, ¿no sería posible llegar a la comprensión más profunda del ser finito?" ${ }^{57}$-y en nuestro caso, ¿de la especificidad de la mujer?

Edith Stein recuerda que "históricamente se deja ver que los intentos para captar conceptualmente la doctrina revelada de la Santísima Trinidad dieron lugar a la formación de los conceptos filosóficos de "hipóstasis" y de "persona". Según la autora, "Gracias a estos conceptos, se ha adquirido algo esencial no solo para la comprensión de la revelación de Dios en tres personas, sino también para la comprensión del ser humano y, en una palabra, lo real-cósico. Desde este aspecto tratamos ahora de ayudarnos de la Revelación para el conocimiento del ser finito" ${ }^{58}$ en su especificidad de mujer. Constata la autora: "La doctrina de la fe señala la unidad de la 'sustancia' (esto es, de la esencia) en las tres personas: así ellas son totalmente iguales y son uno. Se diferencian por las 'relaciones': el Padre 'engendra' al Hijo, el Padre y el Hijo ‘exhalan’ al Espíritu Santo. A esta distinción se añade todavía la diferencia en la aparición temporal de la segunda y de la tercera persona: solo el Hijo nació de la Virgen, fue crucificado, murió y fue sepultado; solo el Espíritu Santo apareció bajo las

56 SFE 951 EES 303: Es hat sich uns selbst als das Sein in Person, ja als dreipersönliches Sein enthüllt. Wenn der Schöpfer das Urbild der Schöpfung ist, muss sich dann nicht in der Schöpfung ein wenn auch noch so fernes Abbild der Drei-Einheit des urprünglichen Seins finden? Und sollte von daher nicht ein tieferes Verständnis des endlichen Seins zu gewinnen sein?

57 SFE 951 EES 303 Damit war etwas Wesentliches nicht nur für das Verständnis de Offenbarung von der Dreipersönlichkeit Gottes, sondern auch für das Verständnis des menschlichen Seins und des Dinglich-Wirklichen überhaupt gewonnen. Von dieser Seite her wollen wir nun auch versuchen, die Offenbarung für die Erkenntnis des endlichen Seins fruchtbar zu machen.

58 SFE 952 EES 303: Die Glaubenslehre hebt die Einheit der "Substanz" (d.h.hier: des Wesens) in allen drei Personen hervor: dadurch sind sie völlig gleich und sind Eines. Das Unterscheidende sind die" Relationen": dass der Vater den Sohn "erzeugt" und Vater und Sohn den Heiligen Geist "hauchen". Dazu kommt der Unterschied in der zeitlichen Erscheinung der zweiten und dritten Person: nur der Sohn ist aus der Jungfrau geboren, gekreuzigt, gestorben und begraben, nur der Heilige Geist in Tauben und Zungengestalt erschienen. 
formas de paloma y de lenguas" ${ }^{59}$.

Edith Stein luego da un paso más, cuando explica: "Las relaciones no pueden ser accidentales, puesto que no son mutables como toda cosa finita...Así, es necesario distinguir de la sustancia... la hipóstasis en cuanto su soporte. A la unidad de la sustancia se contrapone una trinidad de soportes. Si los llamamos persona, es solamente una manera de expresar en palabras humanas lo inefable [...] Todo lo que llamamos generalmente persona...es "rationalis naturae individua substancia" (seres particulares de una naturaleza dotada de razón) en el sentido que contiene en su quid algo de 'inmediato', algo que no comparte con otro. Ahora bien, aquí nos encontramos ante tres personas que poseen en común todo su quid y de las que ninguna es posible sin las otras. Y las tres personas no son más que una sola: la perfección infinita, propia de cada uno, y que no puede ser aumentada" ${ }^{60}$. Sin duda, emerge aquí una verdad clave para la intelección de la especificidad de la mujer en cuanto "soporte" particular del ser común.

No cabe duda de que Edith Stein sigue a Tomás en sus esfuerzos por aclarar el significado de "persona" - estar dotado de razón-e "hipóstasis" -soporte- y su aplicación "analógica” a Dios. De ahí que explica: "Lo que es 'soportado' es la esencia divina, una, indivisible y las tres personas constituyen sus soportes. Esta noción de soporte de esencia me parece muy significativa para la estructura de todo ente" ${ }^{61}$. Pero insiste "aquí no

59 SFE 953 EES 303: Akzidentiell aber können die Relationen nicht sein, weil sie nicht-wie bei allem Endlichen-veränderlich sind [...] So ist es nötig, von der Substanz [...] die Hypostase als ihren Träger zu unterscheiden. Der Einheit der Substanz steht eine Dreiheit von Trägern gegenüber. Wenn wir sie Person nennen, so ist das nur eine menschliche Redeweise, um Unsagbares auszudrücken. Alles, was wir sonst Person nennen...ist "rationalis naturae individua substantia" (Einzelwesen von vernüftiger Natur) in dem Sinne, dass es in seinem Was etwas "Unmittelbares" enthält, etwas, was es mit keinem andern teilt. Hier aber stehen wir vor drei Personen, die ihr ganzes Was gemeinsam haben und von denen keine ohne die andern möglich ist. Und die drei Personen sind nicht mehr als eine: die unendlcihe Vollkommenheit, die einer jeden für sich eigen ist, ist unvermehrbar.

${ }^{60}$ SFE 955 EES 306: Das was "getragen” wird, ist das eine, unteilbare göttliche Wesen, und die Personen sind es, die es tragen, Dieser Begriff des Wesensträgers scheint mir höchst bedeutsam für den Aufbau alles Seienden.

${ }^{61}$ SFE 955 EES 306: Es kam hier nicht ein verschiedener Stoff als "Träger" einer allgemeinen Wesensform in Betracht, um die Personen voneinander zu unterscheiden (wie es bei den Körperdingen geschah) noch eine inhaltliche Unterscheidung verschiedener Formen als "Träger" verschidenener Eigenschaften (wie bei den ge- 
conviene considerar una materia diferente como 'soporte' de una forma universal de esencia para distinguir las personas entre sí...ni una diferencia de contenido en las diversas formas en cuanto 'soportes' de diversas cualidades: la espiritualidad, la unidad y la simplicidad de la esencia divina no dejaban otra cosa que un soporte totalmente desprovisto de materia y de contenido; un soporte que no es más que soporte, en cuanto forma vacía de plenitud esencial. Hemos llegado a esta forma vacía del soporte por conexiones completamente diferentes. El 'yo puro' nos ha parecido ser como 'soporte' del contenido de la vivencia, la persona (finita) como soporte de su particularidad, la forma de la cosa como soporte de su llenado de contenido y en la concepción más general del ente en cuanto tal el 'objeto' o el 'algo' como nos ha parecido como el soporte del quid y del ser" ${ }^{\prime 2}$, lo cual resulta sumamente relevante para la comprensión de la especificidad de la mujer.

Pero Edith Stein no se detiene aquí, sino pasa, luego, a abordar el ser más íntimo de Dios que es amor, para constatar: "El amor en esta máxima realización, abarca, por tanto, el conocimiento. Es a la vez pasivo y acto libre. De esta manera abarca también la voluntad y constituye la realización del deseo. Pero el amor, en su máxima perfección, no es realizado más que en Dios: en el amor recíproco de las personas divinas, en el ser divino dándose a sí mismo. El amor es el ser de Dios, la vida de Dios, la esencia de Dios. Corresponde a cada una de las personas divinas y a su unidad $[\ldots]$ el amor es lo más libre que hay, porque no dispone solo de

schaffenen reinen Geistern): die Geistigkeit, Einheit und Einfachheit des göttlichen Wesens liess nicht anderes übrig als einen völlig stoff-und inhaltslosen Träger-einen, der nichts anders ist als Träger, als leere Form der Wesensfülle. Wir sind in ganz verschieden Zusammenhängen auf diese Leerform des Trägers gestossen. Das "reine Ich" erschien uns als Träger der Erlebnisfülle, die (endliche) Person als Träger ihrer Eigenart, die Dingform als Träger ihrer Inhaltsfülle und in der allgemeinsten Fassung des Seienden als solchen der "Gegestgand" oder das "Etwas" als Träger des Was und des Seins.

${ }^{62}$ EES 382: Die Liebe in dieser höchsten Erfüllung schliesst also die Erkenntnis ein. Sie ist zugleich Empfangen und freie Tat.So schliesse sie auch den Willen ein und ist Erfüllung des Verlangens. Die Liebe in ihrer höchsten Vollendung ist aber nur in Gott verwirklicht: in der Wechselliebe der göttlichen Personen, in dem sich selbst hingebenden göttlichen Sein. Die Liebe ist Gottes Sein, Gottes Leben, Gottes Wesen. Sie entspricht jeder der göttlichen Personen und ihrer Einheit [...] Sie ist [...] das freieste, was es gibt, denn sie verfügt nicht nur über eine einzelne Regung, sondern über das ganze eigene Selbst, die eigene Person... Immer muss sie aber Hingabe sein, um echte Liebe zu sein. 
una emoción aislada, sino del conjunto del propio yo, de la propia persona [...] el amor debe ser siempre don de sí, para que sea auténtico amor"63. En efecto, la autora llega aquí a la cercanía mayor de lo que para ella es lo más específico de ser mujer.

Pero todavía afina su explicación, cuando recuerda ${ }^{64}$ : "Hemos considerado el Verbo Eterno, el Logos, como la unidad del sentido que contiene en sí toda la plenitud de todo sentido como el arquetipo de todas las unidades de sentido finitas". Y prosigue: "En su Credo la Iglesia designa al Espíritu Santo como la fuente de vida, el 'vivificador'. Ahora bien, solo puede vivificar aquel mismo que no recibe la vida, sino que es 'la vida en persona'. También podemos ver en el Espíritu Santo la plenitud de vida divina. Es apenas necesario acentuar el hecho de que esto no implica ninguna división en la esencia divina. La esencia una, que es propia a todas las personas divinas, es vida y amor, sabiduría y poder. Fuera de las relaciones de las personas entre sí, no se puede decir nada de una persona que no convenga igualmente a las otras. Cuando distinguimos 'cualidades' (atributos) en la unidad indivisible de Dios y cuando atribuimos particularmente (apropiamos) unas a tal persona, otras a otra, son tentativas destinadas a hacer comprensible lo que es incomprensible. Sin embargo, lo que la criatura hecha a imagen del creador nos descubre del arquetipo divino es apropiado para mostrar el ser creado en una nueva luz" ${ }^{\prime 5}$, es decir, la especificidad de la mujer.

63 EES 354: Wir haben das Ewige Wort, den Logos, als die Einheit des Sinnes angesehen, die alle Sinnfülle in sich schliesst als das Urbild aller endlichen Sinneinheiten. Als den Urheber des Lebens, den "lebendigmacher", bezeichnet die Kirche in ihrem Credo den Heiligen Geist, Lebendigmachen kann aber letzlich nur, wer selbst das leben nicht empfängt, sonderna das "Leben in Person ist".So dürfen wir im Heiligen Geist die göttlichen Lebensfülle sehen. Es braucht kaum noch betont zu werden, dass darin keine Aufteilung des göttlichen Wesens ausgesprochen sein soll. Das eine Wesen, das allen göttlichen Personen eigen ist, ist Leben und Liebe, Weisheit und Macht. Es kann-ausser den Beziehungen der Personen untereinander-nicht von einer Person ausgesagt werden, was nicht auch den andern zukäme. Es sind Versuche, das Unfassbare fassbar zu machen, wenn wir in der unteilbaren Einheit Gottes "Eigenschaften" (Attribute) unterscheiden und wenn wir die eine dieser, die andere jener Person besonders zuschreiben (approprieren). Dennoch ist das, was das geschöpfliche Abbild uns vom göttlichen Urbild aufschliesst, geeignet, uns das geschöpfliche Sein in einem neuen Licht zu zeigen.

${ }^{64}$ EES 354: Es ist also die dreifaltige Gottheit, in der wir das Urbvild dessen suchen, was wir im Bereich des geschöpflichen als Sinn und Lebenfülle bezeichen.

65 EES 354: Es ist also die derifaltige Gottheit, in der wir das Urbvild dessen suchen, was wir im Bereich des geschöpflichen als Sinn und Lebenfülle bezeichen. 
Sintetizando, la autora concluye efectivamente: "Si en el Hijo la sabiduría divina se ha hecho persona, en el Espíritu, amor. Si por el lado humano, en la naturaleza masculina predomina el entendimiento y en la mujer el sentimiento, entonces se entiende que se intente continuamente poner a la naturaleza femenina en la unión especial con el Espíritu Santo"66. Esto debe dilucidarse con mayor detención sobre todo en vista de la capacidad más propia del Espíritu Santo, el salir de sí y la relevancia analógica que tiene esta capacidad para la comprensión de lo femenino.

\section{c. El Espiritu Santo: salir de si y lo femenino}

En su obra temprana Edith Stein afirma tajantemente: "Dado que el Espíritu Santo es la divinidad en cuanto que sale de sí y entra en las criaturas, la fertilidad creativa y plenificadora de Dios, podemos volver a encontrarla también en esa especificidad de ser 'madre de los vivientes', de hacer brotar de su vida nueva vida, y cuando ha alcanzado autonomía existencial, ayudarla en orden a su más pleno desarrollo posible" ${ }^{97}$. Posteriormente, procede con mayor cuidado sobre todo, en su obra magna "Ser finito y el Ser eterno", cuando allí insiste: "Se trata entonces de buscar en la divinidad trinitaria el arquetipo de lo que hemos designado en el campo de lo creado como sentido y plenitud de vida" ${ }^{98}$. Se refiere entonces a la estrecha interrelación entre el Espíritu Santo y la vida, que concibe, de modo arquetípico, en referencia a la mujer.

La autora explica luego: "Para comprender ahora cómo el Espíritu Santo es el dispensador de la vida y el arquetipo de la vida creada (en la medida en que se puede hablar aquí de "comprensión”), conviene inmediatamente considerar, primero, la posición de la tercera persona en la divinidad. Como ya hemos recalcado anteriormente, no existe entre las per-

${ }^{66}$ F 105: Wenn im Sohn die göttlliche Weisheit Person geworden ist, im Geist die Liebe- wenn auf der anderen Seite in der männlichen Natur der Verstand vorherrschend ist, in der Frau das Gemüt, so versteht man es, dass immer wieder der Versuch gemacht wird, die weibliche Natur in eine besondere Verbindung mit dem Hl.Geist zu bringen.

${ }^{67}$ La mujer 105 F 105: Wenn der HL.Geist die Gottheit ist, sofern sie aus sich selbst ausgeht und in die Geschöpfe eingeht, die erzeugende und vollendende Fruchbarkeit Gottes, so können wir sie wiederfinden in der Bestimmung der Frau "Mutter der Lebendigen" zu sein, durch ihr Leben neues Leben hervorzubringen und ihm, wenn es selbständiges Dasein gewonnen hat, zu seiner möglichst vollkommenen Entfaltung zu verhelfen.

68 EES 354 : Es ist also die Dreifaltige Gottheit, in der wir das Urbild dessen suchen, was wir im Bereich des geschöpflichen als Sinn und Lebensfülle bezeichnen. 
sonas otra diferencia más que la de sus relaciones recíprocas, que pueden explicarse por la manera de sus procesiones. El Padre lleva el nombre de Padre porque todo viene de Él y Él no proviene de nadie. El Hijo se llama Hijo porque viene del Padre y 'se dice Verbo del Padre porque procede del Padre en cuanto que es engendrado por la actividad del intelecto, como engendrado del Espíritu, igual que en nosotros lo originado interiormente por el Espíritu se llama palabra'. La tercera persona se llama 'Espiritu Santo' porque procede del Padre y del Hijo por medio de una espiración única según el modo del amor; es el primero y supremo amor, que mueve los ánimos y los conduce a la santidad que consiste en el último término en el amor a Dios" $"$.

Edith Stein recuerda para seguir explicando: "Hemos tratado de comprender la pluralidad de las personas divinas partiendo del hecho de que Dios es amor, pero que el amor es una libre autoentrega del yo a un tú y un ser uno en nosotros ${ }^{70}$. Puesto que Dios es espíritu, es transparente a sí mismo y genera desde toda la eternidad la 'imagen' de su Ser, en la que Él se ve en sí mismo, es decir, su Hijo idéntico a Él en esencia, la Sabiduría o el Verbo. Puesto que Dios es el amor, lo que él engendra como su 'imagen’ es, pues, amor y la relación recíproca del Padre y del Hijo es amante entrega de sí y ser-uno en el amor. Pero ya que el amor es lo más libre que hay, es entregarse a sí mismo como acto del que se posee a sí mismo, es decir, de una persona-sin embargo, en Dios, es el acto de una persona que no existe y no ama como nosotros, sino es el amor mismo o cuyo ser es amor- por eso el amor divino debe ser persona: la persona del amor. Cuando

${ }^{69}$ EES 354 Um nun den Heiligen Geist den Heiligen Geist als Lebenspender und Urbild des geschöphfilichen Lebens zu verstehen (so weit hier von "Verstehen" die Rede sein kann), muss erst über die Stellung der dritten Person in der Gottheit etwas gesagt werden. Wie schon früher hervorgehoben wurde, gibt es zwischen den Personen keinen anderen Unterschied als den ihrer Beziehung zueinander, die durch die verschiedene Art ihres Hervorgehens erläutert werden. Der Vater heisst Vater, weil von Ihm alles, Er aber von niemandem ausgeht. Der Sohn heisst Sohn, weil Er vom Vater ausgeht. Und "Er wird Wort des Vaters genannt, weil Er vom Vater als Erzeugnis der Verstandestätigkeit hervorgeht, als eine Geistesgeburt, wie auch in uns das innerlich vom Geist hervorgebrachte Wort gennant wird. Die dritte Person heisst "Heiliger Geist, "weil sie vom Vater durch den Sohn in einer einzigen Hauchung in der Weise der Liebe hervorgeht, und ist die erste und höchste Liebe: sie bewegt und führt die Herzen zur Heiligkeit, die letzlich in der Liebe zu Gott besteht”.

${ }^{70}$ EES 355: Wir haben versucht, die Mehrheit der göttlichen Personen von daher zu verstehen, dass Gott die Liebe ist, die Liebe aber freie Selbsthingabe des Ich an ein Du und Einssein beider im Wir. 
el Hijo y el Padre se aman uno al otro, su entregarse es al mismo tiempo un acto libre de la persona del amor" ${ }^{211}$.

La autora prosigue con su explicación y acota: "Pero el amor es vida en la más alta perfección: ser que se da eternamente sin experimentar ninguna disminución, la fecundidad infinita. Por eso el Espíritu Santo es el don: no solo la entrega de las personas divinas entre sí, sino el darse de la divinidad hacia fuera; el (Espíritu Santo) contiene en sí todos los dones que Dios hace a las criaturas. Ya que la sabiduría de Dios ha previsto eternamente todo lo creado, por eso el Logos en cuanto la sabiduría en persona es, pues el arquetipo que abarca toda determinación de esencia de las criaturas, todo lo que ellas deben ser. Puesto que la voluntad creadora de Dios, su amor que suscita la existencia y dispensa la vida, ha dado a las criaturas desde la eternidad la potencia de ser o fuerza para desplegar su esencia, por eso el Espíritu Santo en cuanto la persona de la vida y del amor, es el arquetipo de toda vida creada y de todo acto y de esa irradiación espiritual de la esencia propia, que es propio también de las hechuras materiales", aunque esto vale de modo especial para la mujer.

De ahí que Edith Stein concluye: "En definitiva, si podemos ver en el ser por sí subsistente de cada realidad autónoma [...] una imagen del Padre en cuanto del primer comienzo incondicionado, entonces la estructura del ente creado en cuanto 'algo que es', es una imagen de la Divinidad Trinitaria. Pero puesto que el ente es uno, la 'forma vacía' no existe jamás sin plenitud, y la plenitud de la esencia, es la vez sentido y fuerza, que se configura en la existencia; así pues, la unidad de la esencia divina está igualmente imitada en este ente", sea él varón o mujer.

Sintetizando los resultados obtenidos referentes al segundo aspecto de la presente búsqueda, que trató de esclarecer la cuestión de la especificidad de la mujer a partir de su origen fundante trinitario, podemos constatar que desde este origen emerge una identificación analógica de la naturaleza específica de la mujer con respecto al Espíritu Santo, dador de vida y amor

71 EES 355 Weil Gott die Liebe ist, darum ist das, was Er als Sein "Bild" erzeugt, wiederum Liebe und das Wechselverhältinis von Vater und Sohn liebende Selbsthingabe und Einssein in Liebe. Weil aber die Liebe das Freieste ist, was es gibt, Sichselbstverschenken als Tat eines Selbstbesitzenden, d.h. einer Person- bei Gott aber Tat einer Person, die nicht, wie wir, ist und liebt, sondern die Liebe selbst ist oder deren Sein Liebe ist-darum muss die göttliche Liebe selbst Person sein: die Person der Liebe. Wenn Sohn und Vater einander lieben, so ist ihr Sichverschenken zugleich freie Tat der Person der Liebe. 
por antonomasia. Tal identificación confirma la explicitación steiniana de la especificidad de la mujer por el Gemüt, ya que el nexo indisoluble entre mujer-amor-vida se afina a la luz de las hipóstasis divinas, que tienen todo en común excepto sus relaciones opuestas en cuanto Padre, Hijo y Espíritu Santo. La destacada interrelación analógica del Espíritu Santo con la especificidad de la mujer, sin embargo, no constituye una abstracción etérea, sino que se verifica en la historia humana a través de la permanente colaboración amorosa de la mujer con el varón al servicio de la vida. Esto conlleva una triple exigencia para la concreción de la especificidad de la mujer, es decir, el desarrollo de su humanidad, de su feminidad, de su individualidad. No son fines separados, como tampoco la naturaleza del individuo concreto es tripartita, sino uno: la naturaleza humana en su troquelado específicamente femenino e individual ${ }^{72}$. De hecho, la mujer "no es solo mujer", por lo cual su especificidad, analogada con el Espíritu Santo, requiere de un despliegue detenido.

\section{La especificidad de la mujer en cuanto "mujer no solo mujer"}

Si bien hemos sacado a la luz los elementos constitutivos de la especificidad de la mujer, gracias a un método apto para tal cuestión ${ }^{73} \mathrm{y}$ hemos remontado dicha especificidad vía analógica al misterio trinitario como su origen fundante ${ }^{74}$, centrada en la relación del Espíritu Santo con lo

72 La mujer 234.

73 SFE 986s"Nuestro conocer sigue una marcha progresiva: partimos de lo que nos es inmediatamente accesible y nos abrimos poco a poco un camino hacia lo que no podemos captar directamente, por medio del pensar discursivo, de juicios y conclusiones. Así, en un movimiento continuo acumulamos un tesoro creciente de conocimientos, a pesar de los numerosos desvíos y rodeos causados por ilusiones y errores. Pero este movimiento está orientado hacia una meta y un descanso en la meta. Este fin es la visión del ente. En este ámbito del conocimiento sensible se trata de la percepción sensible, pero considerada no como una simple "impresión" sensible, sino como una intuición llena de espíritu, que nos hace comprender. En el ámbito del pensar discursivo se trata del conocimiento en un estado de cosas. Para toda la diversidad de diferentes esfuerzos de conocimiento, correspondientes a los diferentes géneros del ente, se podría mostrar en cada caso hacia qué clase de intuición plenificante se dirigen. Cuando hemos alcanzado esta meta, experimentamos durante un instante una paz que tiene algo de felicidad. Pero este descanso no es jamás de larga duración, porque siempre alcanzamos una meta parcial que nos conduce más allá de ella y nos propone nuevas tareas.

74 SFE 987: "De todas maneras, la intuición plenificante en la cual podemos descansar es un conocimiento en el sentido propio del término; todo el esfuerzo en el pensar es solo un medio y un camino que conduce a este fin. Y fundándose en la experiencia 
femenino y la mujer, queda por concretar tal relación a través del "ser persona"75, sostenido por la permanente donación constituyente -naturaleza- y gratuita- ${ }^{76}$-del cuerpo y su forma, el alma-, donación que, para Edith Stein, emerge, a la luz de la influencia de Dionisio Areopagita, desde la oscuridad de la interioridad del ser humano en cuanto espíritu al

del descanso, una vez alcanzada la meta, llegamos a la idea de un espíritu que no se fatiga en el camino, puesto que desde el comienzo descansa allá donde está nuestra meta: en la intuición de la plenitud del ente. Abarcando sencillamente todo ente desde su origen esta posesión puede hallarse solo en el espíritu que es él mismo la plenitud del ser y que da el ser a todo ente: en Dios. Pero se puede pensar también en espíritus finitos que están constituidos de tal manera que la plena medida de conocimiento, para el cual por naturaleza son capaces, les es propio desde el inicio de su existencia; y este conocimiento está libre de ilusiones y de errores, en la unidad conclusa de una vida enteramente llena sin disminución ni relajamiento. Este espíritu solo podría poseer en sí un crecimiento de conocimiento si fuese elevado por encima de su propia naturaleza y si Dios le comunicase algo de la plenitud infinita e inagotable de su ser. A tal comunicación la llamamos gracia. Dionisio le da el nombre de iluminación. Por ahora nos limitaremos al conocimiento natural de los ángeles. Por lo tanto se trata de la prerrogativa que tiene el conocimiento humano: pues se presenta como un descanso en la meta, una visión espiritual del ente en su plenitud. Esta prerrogativa la relaciona con otro carácter esencial de los espíritus puros del que todavía tenemos que tratar: no se desarrollan sino que entran acabados en la existencia. Pero, debemos detenernos todavía un poco en su vida espiritual".

75 SFE 992: "La gracia quiere ser recibida personalmente. Es una llamada de Dios, un llamar a la puerta, la persona llamada debe oír y abrir: abrirse a Dios que quiere entrar en ella. Por eso la disponibilidad, la potentia oboedientiae en el sentido estricto y propio del término, es la inclinación a obedecer, a escuchar a Dios y a abandonarse a Él, en libertad. Se trata de una actitud de persona a persona y hace posible ese ser uno que solo es posible entre personas: el ser uno de la unión por la gracia. Así la gracia supone la libertad y supone la naturaleza, ya que tiene que haber criaturas libres para que la acción de la gracia pueda empararse. Pero la naturaleza no supone a su vez la libertad y no es recibida personalmente. Las criaturas se encuentran con su naturaleza en la existencia y no pueden aceptarla o rechazarla como la gracia".

76 SFE 991: potentia oboedientialis la disposición para recibir el ser divino. Santo Tomás afirma que gracias a esta disposición "puede producirse en la criatura todo lo que el Creador quiere realizar en ella". "La gracia es lo que une a Dios y a la criatura en uno. Si la consideramos tal como ella es en Dios, es el amor divino o el ser divino en cuanto bonum effusivum sui, en cuanto bien que se desborda y su comunica (pero que se conserva sin sufrir disminución). Si consideramos la gracia como lo que se encuentra en la criatura, es lo que la criatura recibe en sí como participación del ser divino, es decir, una semejanza participada de la naturaleza divina, algo limitado y creado, pero perceptible en forma ilimitada partiendo de la fuente inagotable del ser divino infinito". 
modo del Espíritu, Dios ${ }^{77}$, ligado al Gemüt -el “alma del alma”- ${ }^{78}$, y dando relieve, de modo incluyente, no excluyente, a la especificidad de la mujer y sus tareas en cuanto necesitada de formación y plenificación ${ }^{79}$.

\section{a. El "ser en persona" y el Espíritu divino}

Llama la atención que para Edith Stein el ser persona humana no es un hecho meramente natural, sino que va ligado al "Yo Soy el que Soy", interpretado por Agustín en cuanto nombre divino, es decir, el Sein in Person involucra la relación naturaleza y gracia ${ }^{80}$. Pues, afirma la autora, "La búsqueda del sentido del ser condujo al primer ser: el 'ser en persona' y también en tres personas" $"$. Y prosigue: "Para comprenderlo en la medida en que es todavía posible una comprensión, y para obtener una nueva

77 SFE (Bellas Páginas): "El don de sí a Dios es [...] al mismo tiempo, don al sí de Dios que es amado y a la creación entera, es decir, a toda esencia espiritual unida con Dios [...]. La vida divina que se desarrolla en el alma amante de Dios no puede ser diferente de la vida trinitaria de la divinidad. El alma se da al ser trinitario; se entrega a la voluntad paterna de Dios que, por así decirlo, engendra de nuevo a su Hijo en ella. Se une al Hijo y querría perderse en él a fin de que el Padre no vea ya nada en ella más que al Hijo. Su vida se une al Espíritu Santo, se transforma en una efusión de amor divino. Es evidente que esta imagen de Dios en el espíritu creado gracias a la unión de amor, fruto de la gracia y de la gloria, no es compatible con ninguna imagen simplemente natural. La palabra imagen ya casi no es el término adecuado. Debe ser comprendida en el sentido en que se dice que el Hijo es imagen del Padre. Se trata de una auténtica filiación divina".

78 335: "Nuestro conocimiento constituye el fundamento sobre el que nos apoyamos para llegar hasta el ente y actuar en el mundo. Conocer las cosas forma parte de esto: captarlas en el significado que ellas poseen para nosotros y en el significado que tienen unas cosas para otras. Este significado se manifiesta en nuestra interioridad cuando captamos de una manera viva su valor; este, considerado como una respuesta que viene de la interioridad, exige objetivamente cierta toma de posición del ánimo - Gemütes 335 - y de la voluntad e incita a emprender y obrar en la correspondiente manera activa. En nosotros conocer, sentir, querer y obrar no están ciertamente separados por completo ni son independientes los unos de los otros, más bien, están condicionados el uno por el otro, porque dependen los unos de los otros, pero todavía no forman una unidad indisoluble".

79 Vida Cristiana de la mujer, 327: nuestro tiempo necesita personas que lleven "en el mundo" una vida consagrada a Dios". ¿Cómo podemos hacer para alcanzar este fin? Como hemos podido recabar de lo dicho respecto a la naturaleza del alma femenina, en ella existe una orientación originaria hacia ese fin; pero en la naturaleza caída existen también impulsos que se le oponen.

${ }^{80}$ EES 293:ss.

81 SFE 956 EES 307: Das Suchen nach dem Sinn des Seins hat uns bis zum ersten Sein geführt: zum "Sein in Person", ja in drei Personen. 
comprensión del ser finito, partiendo del primer ser, hemos aclarado lo que es necesario entender por 'persona'. Pero el ser persona en cuanto tal y por consiguiente el primer ser mismo siguen siendo para nosotros totalmente oscuros si no llegamos a poner en una mayor claridad otra cosa más de lo que hemos ya considerado, a saber, la esencia del espiritu”"82.

En efecto, afirma Edith Stein: "Se ha concebido el ser divino como espiritual. Y si hemos considerado la persona en cuanto soporte de una naturaleza dotada de razón, así su naturaleza espiritual aparece entonces expresada también, pues 'espíritu' y 'razón’ parecen convenir uno al otro inseparablemente. Ahora bien ¿qué significa 'espíritu’? Ya hemos tratado de buscar un acceso a esta pregunta desde diversos aspectos. Hemos designado lo espiritual como lo no espacial y no material; como lo que posee un 'interior' en un sentido completamente no espacial y permanente 'en sí', en cuanto sale de sí. Este 'salir de sí' le es de nuevo esencialmente propio: no como si no tuviera un 'en sí', sino porque entrega enteramente su 'él mismo' sin perderlo, y en esta entrega se manifiesta enteramente, en contraposición a la soledad anímica" $"$.

Para esclarecer esto la autora vuelve sobre el misterio trinitario fundante e insiste: "En la entrega de sí total de las personas divinas, en la cual cada una se enajena enteramente de su esencia y, sin embargo, la conserva perfectamente, cada una está enteramente en sí misma y enteramente en las otras, tenemos ante nosotros el espíritu en su realización más pura y perfecta. La divinidad trina es el verdadero 'reino del espíritu', simple-

82 EES 307: Um es zu verstehen, soweit hier noch ein Verstehen möglich ist, und um auf Grund des ersten Seins dann ein neues Verständnis des endlichen Seins zu gewinnen, ist die Klärung dessen, was "Person" besagt, unternommen worden. Aber das Personsein als solches und damit das erste Sein selbst völlig im Dunkeln, wenn es nicht gelingt, noch etwas anderes zu grösserer Klarheiit zu bringen, als es bisher geschehen ist, nämlich das Wesen des Geistes

83 EES 307: Das göttliche Sein ist als geistiges in Anspruch genommen worden. Und wenn die Person als Träger einer vernunftbegabten Natur bezeichnet wurde, so scheint auch damit ihre Geistnatur ausgesprochen zu sein, denn "Geist" und "Vernunft" scheinen untrennbar zueinander zu gehören. Was aber besagt "Geist"? Wir haben schon von verschiedenen Seiten her einen Zugang dahin gesucht (Note 21) Das Geistige ist gekennzeichnet worden als das Unräumliche und Unstoffliche; als das, was ein "Inneres" in einem völlig unräumlichen Sinn hat und "in sich" bleibt, indem es aus sich herausgeht. Dieses Aus-sich-herausgehen ist ihm wiederum wesenhaft eigen: es ist das völlig "Selbstlose": nicht als hätte es kein Selbst, sondern weil es sein Selbst ganz und gar hingibt, ohne es doch zu verlieren, und in dieser Hingabe offenbar wird -im Gegensatz zu der Verborgenheit des Seelischen. 
mente lo ‘supraterreno'. Toda espiritualidad o cocapacitación del espíritu por parte de las criaturas significa una 'elevación' en este reino, aunque en sentidos diferentes y de diversas maneras" ${ }^{\prime 4}$.

Edith Stein pregunta: “¿Cuál es el lazo entre la espiritualidad y lo correspondiente a la persona? Por persona hemos entendido el soporte de la esencia y específicamente el soporte de una naturaleza dotada de razón. El hecho de poseer la razón distingue a la persona de la hipóstasis en cuanto soporte de la esencia en el sentido amplio. Si existe entre las dos una diferencia verdadera, -este tendrá que ser el caso si una 'forma vacía' y su 'llenado' no solo están unidos exteriormente, sino ligados esencialmente-entonces, no solamente la naturaleza sino también el 'soporte' deben ser algo particular en una persona. Anteriormente hemos llamado al 'yo' soporte de su vida: es aquello de lo que brota la vida interior ('vida interior' en cuanto contraposición a lo que se 'manifiesta' en la configuración material de los llamados 'seres vivos'); es lo que vive en esta vida y la experimenta como suya"85.

De ahí que la autora constata: "Se llama dotada de razón a una criatura que puede comprender la normalidad de su ser propio y según esto puede orientarse con su comportamiento. Además corresponde el entendimiento como don de comprensión y la libertad como don de configurar por sí mismo el propio comportamiento. Si el hecho de poseer la razón pertenece al ser persona, entonces la persona en cuanto tal debe tener

${ }^{84}$ SFE 957 EES 308: In der restlosen Selbsthingabe der göttlichen Personen, in der jede sich ihres Wesens vollkommen entäussert und es doch vollkommen bewahrt, jede ganz in sich selbst und ganz in den andern ist, haben wir den Geist in seiner reinsten und vollkommensten Verwirklichung vor uns. Die Dreifaltige Gottheit ist das eigentliche "Reich des Geistes", das "Überirdische" schlechthin. Alle Geistigkeit oder Geistbegabtheit von Geschöpfen bedeutet eine "Erhebung" in dieses Reich, wenn auch in verschiedenem Sinn und auf verschiedene Weise.

85 SFE 957 EES 308: Wie hängen Geistigkeit und Personhaftigkeit zusammen? Wir haben unter Person den Wesensträger, und zwar den Träger einer vernunftbegabten Natur, verstanden. Die Vernunftbegabung scheidet die Person von der Hypostase als dem Wesensträger im weiteren Sinn. Wenn zwischen beiden ein echter Unterschied vorhanden ist- und das wird der Fall sein müssen, wenn eine "Leerform" und ihre "Fülle" nicht nur äusserlich verbunden sind, sondern wesenhaft zusammengehören-, dann muss nicht nur die Natur, sondern auch das "Tragen" bei der Person etwas Besonderes sein. Es ist früher das "Ich" Träger seines Lebens genannt worden: es ist das, dem das innere Leben entquillt (“inneres Leben" als Gegensatz zu dem in Stoffgestaltung sich "veräussernden" der sogenannten "Lebewesen"), das in diesem Leben lebt und es als das seine erlebt. 
entendimiento y libertad. Llegamos así a la separación del yo y de la persona: no cada yo debe ser necesariamente un yo personal. Al contrario, toda persona debe ser un yo: es decir, ser consciente de su ser propio, puesto que esto pertenece a la dotación de la razón. Lo que interesa en nuestro contexto es comprender la especie particular de "soporte" que se encuentra en el ser persona. Si pertenece al yo como tal el que su vida brote de él y que experimente esta vida como la suya propia entonces el yo personal debe poder además comprender su vida y configurarla libremente desde sí mismo. Así comprendemos que Dios quien en su libertad perfecta configura su propia vida y que es enteramente luz (al que no hay nada escondido) debe ser persona en el sentido más elevado" "86, a la vez que la especificidad de la mujer en cuanto ser en persona emerge en todo su resplandor de criatura.

Sintetizando: la especificidad dilucidada en interrelación con el ser-enpersona, sin duda significa un logro clave y decisivo para comprender el aporte de Edith Stein a la pregunta por la mujer. Sin embargo, todavía hay más por auscultar y preguntar para entender rectamente la especificidad de la mujer en esta autora, "puesto que la vida personal es un salir desde sí y al mismo tiempo un ser y permanecer en sí mismo, pero ambos aspectos caracterizan la esencia del espíritu" ${ }^{\prime 7}$. ¿Cómo se da esto en el ser humano en cuanto "cuerpo vivo" diferenciado en cuanto mujer del varón?

86 SFE 958 EES 309: Vernunftbegabt aber nennt man ein Geschöpf, das die Gesetzlichkeit seines eigenen Seins verstehen und sich mit seinem Verhalten danach richten kann. Dazu gehört Verstand als die Gabe des Verstehens und Freiheit als die Gabe, das eigene Verhalten selbst aus sich heraus zu gestalten. Wenn zum Personsein Vernunftbegabung gehört, dann muss die Person als solche Verstand und Freiheit besitzen. So kommen wir zu der Scheidung von Ich und Person, dass nicht jedes ich ein persönliches zu sein braucht. Dagegen muss jede Person ein Ich sein: d.h. ihres eigenen Seins inne sein, da dies zur Vernunftbegabung gehört. Es kommt in unserem Zusammenhang darauf an, die besondere Art des "Tragens" zu verstehen, die im Personsein liegt. Wenn zum Ich als solchem gehört, dass ihm sein Leben entquillt und dass es dieses Leben als des seinen inne ist, so muss das persönliche Ich überdies sein Leben verstehen und es frei aus sich gestalten können. So verstehen wir, dass Gott, der in vollkommener Freiheti sein Leben selbst gestaltet und der durch und durch Licht ist (dem nichts verborgen ist) im höchsten Sinne Person sein muss.

87 SFE 958 EES 309: Weil das persönliche Leben ein Aus-sich-herausgehen und zugleich ein Sein und Bleiben in sich slebst sit, dieses beides aber das Wesen des Geistes kennzeichnet, darum muss persönliches sein und geistiges Sein schlechthin zusammenfallen. 


\section{b. La relación cuerpo/ espiritu/ alma, una experiencia de simultaneidad donada}

Para Edith Stein, "el ser humano es un ser corporal vivo-anímico-espiritual. En cuanto el hombre es espíritu según su esencia, sale de sí mismo con su 'vida espiritual' y entra en un mundo que se le abre, sin perder nada de sí mismo. Exhala no solo su esencia -como toda hechura real- de una manera espiritual expresándose él mismo de modo inconsciente: además actúa personal y espiritualmente. El alma humana en cuanto espíritu se eleva en su vida espiritual por encima de sí misma. Pero el espíritu humano está condicionado por lo que le es superior e inferior: está inmerso en un producto material que él anima y forma en vista de su configuración de cuerpo vivo. La persona humana lleva y abarca su cuerpo vivo y su alma, pero es al mismo tiempo soportada y abarcada por ellos. Su vida espiritual se eleva de un fondo oscuro, sube como una llama de cirio brillante pero nutrida por un material que él mismo no hace brillar" ${ }^{\prime \prime}$.

Esto lo explica la autora, afinando su argumento, cuando insiste: "Y brilla ella sin ser absolutamente luz: el espíritu humano es visible para sí mismo, pero no es del todo transparente; puede iluminar otra cosa sin atravesarla enteramente. Y hemos conocido sus oscuridades: él conoce por propia luz interior su vida presente y en gran parte lo que era antes su vida presente, pero el pasado comporta lagunas y el porvenir no puede ser previsto con probabilidad segura sino parcialmente, en gran parte es indeterminado e incierto, aunque también es perceptible en esta indeterminación y en esta incertidumbre; origen y meta son absolutamente inaccesibles (si nos atenemos a la conciencia que depende de la vida misma sin ayudarnos la experiencia de otros, del pensamiento que juzga y deduce verdades de fe; son medios de los cuales el espíritu puro no tiene necesidad para conocerse a sí mismo). Y la vida presente inmediatamente cierta

88 EES 310: Das menschliche Sein ist leiblich-seelisch-geistiges Sein. Sofern der Mensch seinem Wesen nach Geist ist, geht er mit seinem "geistigen Leben" aus sich selbst heraus und in eine sich ihm erschliessende Welt ein, ohne dabei sich selbst zu verlassen. Er "atmet" nicht nur- wie jedes wirkliche Gebilde-sein Wesen auf geistige Weise aus, sich selbst unbewusst, aussprechend: er ist überdies persönlich-geistig tätig. Die Menschenseele als Geist erhebt sich in ihrem geistigen Leben über sich selbst. Aber der Menschengeist ist von oben und von unten bedingt: er ist eingesenkt in das Stoffgebilde, das er zu seiner Leibgestalt beseelt und formt. Die menschliche Person trägt und umfasst "ihren"Leib und "ihre" Seele, aber sie wird zugleich davon getragen und umfasst. Ihr geistiges Leben erhebt sich aus einem dunklen Grunde, es steigt empor gleich einer Kerzenflamme, die leuchtet, aber von einem selbst nicht leuchtenden Stoff genährt wird. 
es el cumplimiento fugaz de un instante que cae rápidamente y pronto se nos escapa por completo. Toda la vida consciente no se identifica con 'mi ser'; se parece a una superficie iluminada por encima de una profundidad sombría, que se manifiesta a través de esta superficie. Si queremos comprender el ser persona del hombre, debemos intentar penetrar en esta profundidad sombría" 89 . Y esto significa un desafío peculiar, cuando se trata de una corporalidad tan compleja como la de la mujer.

Edith Stein, en efecto, se adentra en esta complejidad, recordando que "hemos hablado de un doble más allá, en el que el espíritu humano penetra en su vida despierta y consciente: el mundo exterior y el mundo interior ${ }^{90}$. (Por encima de ambos ámbitos, hay caminos que conducen al superior más allá del ser divino) ${ }^{91}$. "Esta constatación nos obliga a dirigir nuestra mirada a un área enteramente nueva: el hecho de que la cabeza tiene relación con el pensamiento, concierne a la gran serie de cuestiones sobre la relación entre el alma y el cuerpo vivo. ¿Qué es el alma? ¿Qué es el cuerpo vivo? ¿Es el alma un algo cósico que percibo y experimento interiormente o es el todo constituido de un cuerpo vivo y de un alma? Se presenta un conjunto de preguntas inquietantes. Tratemos solo de penetrar en ellas hasta el punto en que se hace perceptible la particularidad

89 SFE 959;EES 310-311: Und sie leuchtet, ohne durch und durch Licht zu sein: der Menschengeist ist für sich selbst sichtbar, aber nicht restlos durchsichtig; er vermag anderes zu erhellen, aber nicht völlig zu durchdringen.Wir haben seine Dunkleheit schon kennen gelernt (Note 25): er weiss durch sein eigenes inneres Licht wohl um sein gegenwärtiges Leben und um vieles, was einmal sein gegenwärtiges Leben war, aber das Vergangene ist lückenhaft, das Zukünftige nur in Einzelheiten mit einiger Wahrscheinlichkeit vorauszusehen, in weit grösserem Umfang unbestimmt und ungewiss, wenn auch in dieser Unbestimmtheit und Ungewissheit fassbar, Ursprung und Ziel völlig unzugänglich (solange wir uns an das zum Leben selbst gehörige Bewusstsein halten und nicht fremde Erfahrung, urteilendes und schliessendes Denken oder Glaubenswahrheiten zu Hilfe nehmen-lauter Hilfsmittel, deren der reine Geist zu seiner Selbsterkenntnis nicht bedarf). Und das unmittelbar gewisse Gegenwartleben ist die flüchtige Erfüllung eines Augenblicks, sofort zurücksinkend und sehr bald völlig entgleitend. Das ganze bewusste Leben ist nicht gleichbedeutend mit "meinem Sein"- es gleicht der belichteten Oberfläche über einer dunklen Tiefe, die sich durch diese Oberfläche kundgibt. Wenn wir das menschliche Personsein verstehen wollen, müssen wir versuchen, in diese dunkle Tiefe einzudringen.

90 SFE 960: EES 311: Wir sprachen von einem doppelten Jenseits, zu dem der Menschengeist in seinem schwachen, bewussten Leben vordringt: die äussere und die innere Welt.

91 SFE 962 EES 311:Über beide hinaus führen die Wege in das "höhere" Jenseits des göttlichen Seins. 
de la persona humana, y con ello simplemente la del ser-hombre" 92 y la de ser-mujer. De hecho, concluye la autora: "El yo humano no es solamente un yo puro, ni únicamente un yo espiritual, sino también un yo corporal" 93 .

Pero la autora advierte: "lo que es corporal no es jamás meramente corporal. Lo que diferencia el cuerpo vivo de una simple masa corpórea es la existencia de un alma. Allí en donde hay un cuerpo vivo, existe también un alma. Y al revés: donde hay un alma, allí hay también un cuerpo vivo"94. De ahí que Edith Stein vuelve a insistir: "Hemos considerado (con Hedwig Conrad-Martius) que la particularidad del alma consiste en ser el propio núcleo del ser vivo y la fuente escondida de donde toma su ser para aparecer como figura visible [...] Reafirmamos en primer lugar el significado según el cual el "alma" es el núcleo del ser de las hechuras materiales vivas, de todo lo que lleva "en sí la potencia de autoconfiguración" $" 95$. Por lo cual la especificidad de la mujer no es solo un hecho dado, sino también una tarea por asumir.

Sintetizando, la relación espíritu-yo-cuerpo permite apreciar la especificidad de la mujer como persona espíritu yo a partir de su cuerpo que no solo es cuerpo. Entonces la mujer es mujer, no siendo solo mujer -Keine Frau ist ja nur Frau $-{ }^{96}$ lo cual remite a una configuración singular práctica

92 SFE 963 EES 312: Diese Feststellung lenkt den Blick auf ein ganz neues Gebiet: dass der Kopf mit dem Denken etwas zu tun hat, das gehört in den grossen Fragekreis des Verhältnisses von Leib und Seele. Was ist die Seele? Was ist der Leib? Ist die Seele das dingartige Etwas, das ich innerlich wahrnehme und erfahre, oder ist es das Ganze aus Leib und Seele? Eine verwirrende Fülle von Fragen taucht auf. Wir wollen nur versuchen, uns so weit hindurchzuarbeiten, dass die Eigentümlichkeit der menschlichen Person und damit des Menschseins überhaupt fassbar wird.

93 SFE 963 EES 313: Das menschliche Ich ist nicht nur ein "reines Ich", nicht nur ein geistiges, sondern auch ein leibliches.

94 SFE 964 EES 313: Was aber leiblich ist, das ist niemals bloss leiblich. Was den Leib von einem blossen Körper unterscheidet, ist, dass es ein beseelter Körper ist. Wo Leib ist, da ist auch Seele. Und umgekehrt: Wo Seele ist, da ist auch Leib (Note 27).

95 SFE 964 EES 314: Als Eigentümlichkeit der Seele haben wir es (mit Hedwig ConradMartius) angesehen, dass sie als eigene Seinsmitte des Lebewesens aufzufassen ist und als der verborgene Quell, aus dem es sein Sein schöpft und zu sichtbarer Gestalt aufsteigt (Note 31) [...] Zunächst halten wir den Sinn fest, wonach "Seele" die Seinsmitte der lebendigen Stoffgebilde ist-alles dessen, was die Macht zur Selbstgestaltung in sich trägt" (Note 32).

96 Gerl-Falkovitz Hanna-Barbara,Keine Frau ist ja nur Frau.Texte zur Frauenfrage. Herausgegeben und eingeleitet von Hanna-Barbara Gerl, Feiburg-Basel-Wien 1989,143 pp. 
de la interioridad femenina, que según Edith Stein se orienta por el Gemüt en interrelación con el Espíritu Santo y que como tal tiene sus concreciones connaturales, sostenidas por la gracia.

\section{c. La unión Espiritu Santo-mujer en cuanto especificidad femenina y su concreción}

Como, según Edith Stein, "de la eternidad procede la identidad de la mujer", ella debe vivir sobre fundamento eterno para plenificar su especificidad en este mundo ${ }^{97}$. Si plenifica su especificidad en este mundo, alcanza la vida eterna. "Dios creó al ser humano a su imagen. Como hombre y mujer los creó". Cabe recordar, entonces, lo anteriormente dicho respecto: "Si a los seres humanos no les dispuso en el mundo como especie única, sino doble, también a su existencia debe pertenecerles, junto a uno común, un sentido diferente" ${ }^{98}$. Esto lo explica la autora constatando: "Ambos son formados a imagen de Dios. Y así como cada criatura en su finitud solo puede reflejar un aspecto de la divina esencia, y en la pluralidad de criaturas aparece la unidad infinita y la simplicidad de Dios en una multitud de manifestaciones diferenciadas, así también el género masculino y el femenino podrían entenderse [...] como siendo de distinto modo imagen de la divina protoimagen" 99 .

Si bien para Edith Stein, como se ha visto ${ }^{100}$, "san Agustín y santo Tomás y la tradición subsiguiente vieron en el espíritu del ser humano la imagen de la Trinidad", y que esto, "se entiende de diversas maneras, pero sobre todo de forma que en el ser, en el conocer y en el amar están transmitidos Padre, Hijo y Espíritu Santo", igualmente vale que "Si en el Hijo la sabiduría divina se ha hecho persona, en el Espíritu, amor. Si por el lado humano en la naturaleza masculina predomina el entendimiento y en la mujer, el sentimiento-Gemüt ${ }^{101}$, entonces se entiende que se intente

${ }^{97}$ F 105: Von Ewigkeit her stammt die Bestimmung der Frau. Auf ewigem Grunde muss sie leben, um ihre Bestimmung in diese Welt zu erfüllen. Wenn sie ihre Bestimmung erfüllt, wächst sie ins ewige Leben hinein.

98 Supra F 105

99 La mujer 126-127. F 105: Nach Gottes Bild sind beide geformt. Und wie jedes Geschöpf in seiner Endlichkeit nur einen Bruchteil des göttlichen Wesens widerspiegeln kann, in der Mannigfaltigkeit der Geschöpfe die unendlichen Einheit und Einfachheit Gottes in einer Fülle verschiedenartiger Strahlen gebrochen erscheint, so werden auch männliche und weibliche Art das göttliche Urbild in verschiedener Weise nachbilden.

100 Supra F 105.

${ }^{101}$ Frauenleben im Lichte der Ewigkeit, en Die Frau, 105. 
continuamente poner a la naturaleza femenina en una unión especial con el Espíritu Santo" "102. En esta afirmación steiniana, sin duda, culmina la respuesta a la pregunta por la especificidad de la mujer, a la vez que tal respuesta se proyecta hacia unas concreciones sugerentes.

De hecho, Edith Stein no tarda en abordar tales concreciones, en la medida en que ellas emergen. Pues la autora descifra, a la luz de la secuencia de Pentecostés, unas actitudes significativas que expresan la "unión especial" de la naturaleza femenina con el Espíritu Santo". Pues -según lo citado anteriormente- "Dado que el Espíritu Santo es la divinidad en cuanto que sale de sí misma y entra en las criaturas, fertilidad creativa y plenificadora de Dios, podemos volver a encontrarlo también en esa especificidad femenina de ser 'madre de los vivientes', de hacer brotar de su vida nueva vida, y, cuando ha alcanzado autonomía existencial, en ayudarla en orden a su más pleno desarrollo posible. Como el Espíritu Santo es consuelo y socorro, el que sana lo herido, el que calienta lo helado, el que vivifica lo mortecino, como en tanto que padre de los pobres distribuye todos los buenos dones, entonces volvemos a encontrarlo en todas las obras de amor y misericordia femenina" ${ }^{103}$.

Además, Edith Stein sostiene: "El Espíritu, que limpia lo manchado, que flexibiliza lo rígido, se refleja en la pureza y dulzura femenina, que no solo quiere ser ella misma pura y dulce, sino también expandir la pureza y la dulzura en torno a sí. Por eso el pecado original que afectó a los dos al respecto, es caída del espíritu del amor y con ello caída de la esencia femenina en sí misma. 'Quod Heva tristis abstulit, tu reddis almo germine'. La imagen pura de la esencia femenina está ante nuestros ojos en la Inmaculada, la Virgen, que estaba llena del Espíritu Santo, el templo en el cual construyó su morada y la plenitud de la gracia, todos sus dones. Ella no quiso ser otra cosa que la esclava del Señor, la puerta cuyo través pudiese entrar en la humanidad, pues no solo por sí misma, sino por su "dulce retoño" había ella de volvernos a traer la salvación perdida"

De ahí que la autora deduce una significativa interpretación del misterio de María, que suele designar "Esposa del Espíritu Santo"105: "Como madre de Dios y madre de todos los hijos de Dios, ella está elevada so-

\footnotetext{
${ }^{102}$ La mujer 127.

${ }^{103}$ La mujer 127-128:

${ }^{104}$ La mujer 128

105 Obras completas V, 825-827
} 
bre todos los seres humanos al trono de la gloria, y con ella la condición misma de madre es santificada; como Virgen, muestra la belleza incomparable y la condición de grata a Dios, a la vez que la condición fructífera de la pureza virginal; como reina, la fuerza victoriosa del amor servicial y la pureza inmaculada. A su imagen debe mirar toda mujer que quiere alcanzar su especificidad"106.

En efecto Edith Stein explica: "La naturaleza y la misión de la mujer demandan una formación que pueda conducir a un ejercicio de amor activo. Esto exige ciertamente, como elemento más importante, la formación de la emotividad-Gemüt, pero esta verdadera formación del Gemüt, a la que corresponden la claridad de entendimiento, la energía activa, así como la actividad práctica, hace posible el recto ordenamiento interior adecuado a los valores objetivos y la repercusión práctica de esta actitud”"107.

La autora describe esta práctica natural en la "Novena de pentecostés" en interrelación con el Espíritu Santo: “¿Quién eres tú, dulce luz que me lleva e ilumina la oscuridad de mi corazón? Me conduce igual que una mano materna y si me soltaras, no sabría ni dar un paso. Tú eres el espacio que envuelve todo mi ser y lo encierra en sí, abandonado de ti caería en el abismo de la nada, de donde tu lo elevas al Ser. Tú, más cercano a mí que yo misma y más íntimo que mi intimidad, y sin embargo, inalcanzable e incomprensible, y que hace explotar todo nombre: ¡Espíritu Santo-Amor eterno!" $" 108$.

${ }^{106}$ La mujer, 128.

${ }^{107} \mathrm{La}$ mujer 105: Al rango objetivo de los valores le corresponde que lo supraterreno esté por encima de los valores terrenos. El encauzamiento de esta actitud corresponde a la vez la vocación profesional futura, la de formar seres humanos para el reino de Dios. El núcleo de toda formación femenina (como de toda formación humana en general) debe ser por tanto la formación religiosa, una formación religiosa que sepa exponer las verdaderas de fe conmoviendo el sentimiento y sepa llevar a la acción entusiasta, y que a la vez sea adecuada para abrazar todos los caminos de afirmación práctica de la vida de fe modelando el alma para la vida entera: vivir y orar con la Iglesia mediante el cuidado de la liturgia, inicio de una relación personal con el Señor, sobre todo mediante la comprensión profunda de la santísima eucaristía, y una vida verdaderamente eucarística. Naturalmente, semejante trabajo de formación religiosa solo puede ser llevado adelante por personalidades que estén ellas misma totalmente transidas del espíritu de la fe, y cuya vida se encuentre configurada en tal sentido.

${ }^{108}$ Obras completas V 769 Edith Stein, Verborgenes Leben. Hagiographische Essays. Meditationen. Geistliche Texte (VL) (ESW, XI) Freiburg-Basel-Wien 1987, 175: Wer bist du süsses Licht, das mich erfüllt und meines Herzens Dunkelheit erleuchtet? 
En concreto, para Edith Stein se trata "de despertar en el sentimientoGemüt, alegría por lo verdaderamente bello y bueno, y aversión por lo bajo y vulgar. Es necesario, pues ponerles ante lo que es verdaderamente bello y bueno, pero no solo eso. El sentido del valor de las cosas solo se desarrolla de muchas maneras en el niño cuando ve cómo toma posición al respecto el adulto, especialmente el educador: su entusiasmo suscita entusiasmo" "109. La autora comenta a través de su poesía: “¿Eres tú quien creó el claro espejo, cercano al trono del Altísimo, como un mar de cristal en donde la divinidad se contempla amando? Tú te inclinas sobre la obra más bella de la creación, y resplandeciente te ilumina con tu mismo esplendor, y la pura belleza de todos los seres, unida en la amorosa figura de la Virgen, tu esposa sin mancha: ¡Espíritu Santo-Creador del Universo!”"110.

Pero la autora advierte: "Esta orientación del sentimiento-Gemüt hacia tomas de posición determinadas es a la vez un medio para formar la capacidad de discernimiento ${ }^{111}$. No se le puede poner ante los ojos solamente lo bueno y lo bello, porque la vida le pondrá en contacto también con lo

Du leitest mich gleich einer Mutter Hand, und liessest du mich los, so wüsste keinen Schritt ich mehr zu gehen.Du bist der Raum, der rund mein Sein umschliesst und in sich birgt. Aus dir entlassen entsänk'es in den Abgrund des Nichts, aus dem du es zum Licht erhobst. Du, näher mir als ich mir selbst und innerlicher als mein Innerste und doch untastbar und unfassbar und jeden Namen sprengend: Heiliger Geistewige Liebe

${ }^{109}$ La mujer, $105 \mathrm{~s}$.

${ }^{110}$ Obras completas V 775; VL ,176s: Bist du es, der den klaren Spiegel schuf, zunächst des Allerhöchsten Thron, gleich einem Meer von Kristall, darin die Gottheit liebend sich beschaut? Du neigst dich über deiner Schöpfung schönstes Werk, und strahlend leuchtet dir die eigener Glanz entgegen. Und aller Wesen reine Schönheit vereinigt in der lieblichen Gestalt der Jungfrau, deiner makellosen Braut: Heiliger Geist-Schöpfer des Alls!

${ }^{111}$ La mujer, 105s: no basta con poner en movimiento la emotividad-Gemüt en general. En todos los movimientos del sentimiento-Gemüt hay un momento valorativo: lo que el sentimiento-Gemüt aprehende como significativamente positivo o negativo, ya sea para el ser humano afectado o, con independencia de ello "objetivamente" "en sí". Con esto se hace posible para los movimientos del sentimiento-Gemüt mismo un juicio según lo "correcto" o "falso"," adecuado" o "inadecuado". Hay que diferenciar lo positivo de lo negativo, lo elevando frente a lo bajo, y aprender a situarse al respecto de la forma adecuada. La convivencia con las tomas de postura del entorno constituye el medio más eficaz al respecto; de los influjos voluntarios o involuntarios del entorno depende ampliamente la actitud de la persona adulta ante el mundo de los valores. Y así resulta de extraordinaria importancia que su formación esté en la mano de educadoras cuya emotividad-Gemüt se haya formado adecuadamente. 
negativo, y porque ante ello tendrá que haber aprendido a diferenciar" ${ }^{\prime 12}$. Pero en definitiva, para Edith Stein vencerá el amor y ella puede cantar: “¿Eres tú el dulce canto del amor y del santo recato, que eternamente suena en torno al trono de la Trinidad y desposa consigo los sonidos puros de todos los seres? La armonía que aúna los miembros con la Cabeza, donde cada uno encuentra feliz el sentido secreto de su ser, y jubilante irradia libremente desprendido en tu fluir: ¡Espíritu Santo-Júbilo eterno!”113.

Sintetizando, la formación y el perfeccionamiento de la especificidad femenina se concretan de múltiples maneras a través de actitudes innatas de la naturaleza de la mujer, pero sostenidas por el origen trinitario fundante y especificado en el Espíritu Santo, es decir, por la gracia de Dios. Llama la atención que la autora haga uso frecuente de la vía analógica y explicita la concreción de la especificidad de la mujer en interrelación con los trascendentales, en cuanto nexo feliz entre naturaleza y gracia, pues "Esto es lo bello en todos sus géneros, así como las otras categorías estáticas. Es la verdad, que lanza al espíritu humano buscador a un movimiento nunca aquietado. Es todo aquello que actúa desde el otro mundo en esta vida

${ }^{112}$ La mujer, 105s: Hay también un peligro en este importantísimo e imprescindible medio de formación de la emotividad-Gemüt: sentimientos y tomas de posición afectivas-Gemüt son "contagiosas”, pasan fácilmente de un alma a otra, como simples situaciones personales, que por un lado no tienen ninguna franqueza para los valores expuestos, y además no ocupan ningún lugar en el alma del afectado [...] Entonces no se alcanza ninguna formación verdadera: la apariencia engañosa es tenida por realidad [...] La simple toma de posición sentimental-gemüt debe ser llevada a aquel conocimiento de los valores en donde entendimiento y sentimiento-Gemüt cooperan de forma determinada (mostrar hasta qué punto, excedería los límites de este escrito). Quien comprenda claramente por qué llama a algo bello o bueno, no aceptará tan simplemente las tomas de posición de los demás [...]. Los movimientos del sentimiento-Gemüt son fuerzas impulsivas que inducen a la acción. Quien esté verdaderamente fascinado por el arte sacrificará la comodidad por un goce del arte...Esa educación es responsable de la creación de aquel tipo de mujer que lleva una vida de sueños y de apariencia y que se evade ante los desafíos de la realidad, o se abandona inerme a sentimientos y emociones cambiantes, que va la caza de sensaciones que excitan continuamente al sentimiento-Gemüt y no llega nunca a una serena organización de la vida y a una actividad fructífera."

113 Obras completas V 775. VL ,177: Bist du das süsse Lied der Liebe und der heiligen Scheu, das ewig tönt um des Dreifaltigen Thron, das aller Wesen reinen Klang in sich vermählt? Der Einklang, der zum Haupt die Glieder fügt, darin ein jeder seines Seins geheimnisvollen Sinn beseligt findet und jubelnd ausströmt, frei gelöst in deinem Strömen: Heiliger Geist-ewiger Jubel! 
con poder misterioso y fuerza de atracción" "114, hacia lo cual impulsa el mismo Espíritu Santo, cuando se une al espíritu humano, dispuesto connaturalmente a recibir y a darse, como el de la mujer.

\section{A modo de conclusión}

Debemos admitir que la respuesta a la pregunta por la especificidad de la mujer, pese a todo el esfuerzo realizado, permanece inconclusa, pero sí articula elementos significativos que abren a una nueva búsqueda más intensa y completa. Dicha respuesta se centra en tres núcleos significativos importantes, es decir, la pregunta por el fundamento de la especificidad de la mujer, el método adecuado para abordar dicha especificidad con una racionalidad propiamente teológica y el Gemüt en cuanto elemento constitutivo central de dicha especificidad.

El planteamiento de la pregunta por el fundamento de la especificidad de la mujer es, sin duda, el momento más decisivo del itinerario de búsqueda recorrido. La respuesta emerge en la medida en que la argumentación steiniana se va abriendo a la verdad teológica del misterio de Dios Trino y Uno, es decir, misterio de diversidad en la unidad, de modo hipostático, lo cual origina "el ser en persona", en el cual trasluce el origen fundante a través de los trascendentales del ser. Estos no solo trasparentan el ser común en contornos singulares concretos en cuanto bellos, buenos y verdaderos, sino remontan a través de la imagen, que es la mujer

${ }^{114}$ La mujer, 105s: "Hemos reconocido la emotividad-Gemüt como centro del alma femenina. Por ello deberá ponerse en el centro de la formación de las mujeres la formación de lo emotivo-Gemüt. Lo emotivo vive de sentimientos (tales como alegría, tristeza), estados de ánimo (como serenidad, lobreguez), tomas de posición (entusiamo, aversión), afectos (amor odio). Ellos presentan la confrontación del ser humano con el mundo (y también consigo mismo). Solo quien es conmovido por la vida pondrá en movimiento su emotividad-Gemüt. Quienquiera despertarla, deberá ponerla en contacto con algo que le impacte. Tales son ante todo los destinos de los seres humanos y las acciones humanas tal y como los presentan a las almas juveniles la historia y la literatura y también, naturalmente, y en primer lugar, los acontecimientos de la actualidad. Esto es lo bello en todos sus géneros, así como las otras categorías estáticas. Es la verdad, que lanza al espíritu humano buscador a un movimiento nunca aquietado. Es todo aquello que actúa desde el otro mundo en esta vida con poder misterioso y fuerza de atracción. Religión e historia, la lengua nacional y eventualmente las lenguas extranjeras (si se logra ir más allá de las dificultades lingǘsticas exteriores y alcanzar el contenido espiritual) son en la enseñanza las materias principalmente formadoras de la emotividad-Gemüt. 
junto con el varón, de la Trinidad a las hipóstasis divinas: al Padre como memoria, al Hijo, en cuanto entendimiento, y al Espíritu Santo, nexo de amor. Sin menoscabar el ser divino común, resalta la peculiaridad hipostática intradivina en la cercanía del Padre al sentir, en la lucidez concreta del Hijo y en el nexo de amor del Espíritu Santo.

La especificidad de la mujer encuentra aquí su fundamento último en cuanto interrelacionado, de modo analógico, con el Espíritu Santo-Amor. Esta interrelación de la mujer con el Espíritu Santo no excluye la especificidad del varón -ya que este se encuentra, de modo análogo, prefigurado en el Hijo- sino ambas especificidades se incluyen a partir de sus relaciones opuestas. Esto significa que lo propio y lo otro están en cada uno, varón y mujer, nuestra pregunta reiterada por si Edith Stein admite la dualidad femenina masculina en cada uno-, pues la especificidad de la mujer no destruye la del varón, sino la realza, es decir, la alteridad masculina es constituyente de la ipseidad femenina y viceversa, de modo análogo al Hijo y al Espíritu, teniendo como origen fontal al Padre, principio sin principio, al cual nos asemejamos por medio de nuestro sentir común.

Para abordar tal especificidad de la mujer por un método seguro -según Edith Stein, el problema más serio de la pregunta por la especificidad de la mujer- hemos tratado de seguir el método fenomenológico de la autora, tal como ella lo concibe y lo sigue aplicando hasta en su última obra, cuando habla de la necesidad de "suspender los pensamientos del corazón”. Este método nos proporciona una racionalidad teológica orientada por la objetividad desde la convicción subjetiva inconmovible de que la verdad de la mujer existe. A ella hay que acercarse por medio de la empatía, a través de la cual no solo las cosas mismas revelan su esencia a la luz de la mirada atenta, la intuición, de tal modo que la constitución de la especificidad de la mujer se revela a partir de su realidad corporal compleja, por medio de la cual se expresa el espíritu, quien emerge desde el alma y su última profundidad, "el alma del alma" -Gemüt- en cuanto especificidad propia de la mujer.

Entender esta afirmación, repetida por la autora una y otra vez, sin duda, ha sido la preocupación propiamente tal de la presente investigación. Pero, más que ser la última profundidad del alma femenina, que también posee el varón, aunque de modo menos distinguido -recordemos el "sentir" común del Hijo y del Espíritu en cuanto Padre-memoria-, el Gemüt constituye aquella base natural, que es inhabitada por la gracia tan 
pronto que el Espíritu Santo se une a nuestro espíritu, permitiéndole salir de sí, hacia el otro, sin perder su ipseidad por la constitución a partir de otro, al modo del mismo Espíritu Santo. Tal existencia extática se plasma en la mujer por su inclinación connatural hacia la vida y el cuidado concreto de dicha vida. Si la autora define la especificidad de la mujer por medio de la constitución propia del Gemüt en cuanto instancia profunda del alma, capaz de "entender" a la vez que "valorar", es decir, hacerse cargo de la dimensión valórica de todo cuanto existe, de tal modo, que ello es percibido como bello, bueno, verdadero, sin que su ser se agote en tales apreciaciones, con todo no niega la presencia del Gemüt en el varón, pero sí percibe un desarrollo más concreto en la mujer, que se expresa en una manera de proceder análoga al del Espíritu Santo.

Lejos de haber agotado la concreción de la riqueza de la especificidad femenina, que de ahí emerge, reconocemos que la profundidad y el acierto de un modo de pensar, hecho por una mujer, no solo nos ha enseñado cómo piensa una mujer filósofa a diferencia de un varón filósofo, con quien comparte, indudablemente, el mismo rigor científico y su austeridad conceptual, sino que también nos ha puesto en camino hacia una profundidad aun mayor.

\section{Resumen}

La presente investigación aborda la pregunta por la especificidad de la mujer en la obra de Edith Stein. La respuesta se centra en tres núcleos significativos importantes, es decir, la pregunta por el fundamento de la especificidad de la mujer, el método adecuado para abordar dicha especificidad con una racionalidad propiamente teológica y el Gemüt en cuanto elemento constitutivo central de dicha especificidad. En efecto, la especificidad de la mujer encuentra su fundamento último en Dios Trino y Uno en cuanto interrelacionada, de modo analógico, con el Espíritu Santo-Amor. Esta interrelación no excluye la especificidad del varón, -ya que este se encuentra, de modo análogo, prefigurado en el Hijo- sino ambas especificidades se incluyen a partir de sus relaciones opuestas. Esto significa que la especificidad de la mujer no destruye la del varón, sino la realza, de modo análogo al Hijo y al Espíritu, teniendo como origen fontal al Padre, principio sin principio, al cual nos asemejamos por medio de nuestro sentir común.

\section{Palabras clave}

Mujer, Analogía, Trinidad, Espíritu Santo, Misión. 


\section{Summary}

This research deals with the question by the specificity of women in the work of Edith Stein. The answer is focused on three important significant cores, i.e. the question by the principle of the specificity of women, the appropriate method to address this specificity with a rationality which is genuinely theological, and the Gemüt in the central constituent part of such specificity. Indeed, the specificity of women finds its ultimate principle in the Triune and One and Only God, such interrelated, as analogical way, with the Holy Spirit-Love. This interrelation does not exclude the specificity of the male, since it is found, similarly, prefigured in the Son - but both specificities are included in its opposite relations. This means that the specificity of women does not destroy that of the male, but highlights, analogically to the Son and the Spirit, with the Father, as fontal source, a beginning without beginning, which we are similar to by means of our common feeling.

Key Words

Women, Analogy, Trinity, Holy Spirit, Mission. 